\title{
La fête du Travail à Montréal le premier lundi de septembre, symbole de l'affirmation de la classe ouvrière dans l'espace public (1886-1952)
}

\author{
Jacques Rouillard
}

Volume 64, numéro 2, automne 2010

URI : https://id.erudit.org/iderudit/1017838ar

DOI : https://doi.org/10.7202/1017838ar

Aller au sommaire du numéro

Éditeur(s)

Institut d'histoire de l’Amérique française

ISSN

0035-2357 (imprimé)

1492-1383 (numérique)

Découvrir la revue

Citer cet article

Rouillard, J. (2010). La fête du Travail à Montréal le premier lundi de septembre, symbole de l'affirmation de la classe ouvrière dans l'espace public (1886-1952). Revue d'histoire de l'Amérique française, 64(2), 33-73. https://doi.org/10.7202/1017838ar

\section{Résumé de l'article}

Au Canada et au Québec, la fête légale du Travail est célébrée le premier lundi de septembre. Pourquoi cette fête a-t-elle lieu à cette date ? Rien ne vient marquer ce jour consacré au travail et aucune organisation ne la commémore ou n'en explique le sens. Sa signification originelle est tombée dans l'oubli. Cette journée a pourtant déjà donné lieu à un imposant défilé des travailleurs à Montréal pendant plus de cinquante ans (1886-1952). Organisée par les syndicats internationaux, la marche a réuni, dans un ordre presque militaire, des milliers de travailleurs syndiqués dans les rues avec bannières, drapeaux, plusieurs fanfares et chars allégoriques. En occupant collectivement un espace publique, les syndiqués voulaient manifester de manière symbolique la dignité de leur travail, la force du syndicalisme et leur identité comme classe sociale. C'est dans ce sens également que la manifestation était comprise par les éditorialistes, les hommes politiques et les autorités religieuses. Ce défilé annuel très bien structuré est le plus imposant de l'histoire du Québec en termes de participation au cortège, à tout le moins jusqu'à la Deuxième Guerre mondiale. Après avoir connu une grande popularité, la participation des syndiqués s'effrite après la guerre, la célébration étant victime de changements dans la composition du membership syndical et touchée aussi par l'avènement de la société de consommation.
Tous droits réservés @ Institut d’histoire de l’Amérique française, 2010

Ce document est protégé par la loi sur le droit d'auteur. L'utilisation des services d'Érudit (y compris la reproduction) est assujettie à sa politique d'utilisation que vous pouvez consulter en ligne.

https://apropos.erudit.org/fr/usagers/politique-dutilisation/ 


\section{La fête du Travail à Montréal le premier lundi de septembre, symbole de l'affirmation de la classe ouvrière dans l'espace public (I886-1952) $)^{\mathrm{I}}$

\author{
JACQUES ROUILLARD \\ Département d'histoire \\ Université de Montréal
}

RÉsumÉ • Au Canada et au Québec, la fête légale duTravail est célébrée le premier lundi de septembre. Pourquoi cette fête a-t-elle lieu à cette date ? Rien ne vient marquer ce jour consacré au travail et aucune organisation ne la commémore ou n'en explique le sens. Sa signification originelle est tombée dans l'oubli. Cette journée a pourtant déjà donné lieu à un imposant défilé des travailleurs à Montréal pendant plus de cinquante ans (1886-1952). Organisée par les syndicats internationaux, la marche a réuni, dans un ordre presque militaire, des milliers de travailleurs syndiqués dans les rues avec bannières, drapeaux, plusieurs fanfares et chars allégoriques. En occupant collectivement un espace publique, les syndiqués voulaient manifester de manière symbolique la dignité de leur travail, la force du syndicalisme et leur identité comme classe sociale. C'est dans ce sens également que la manifestation était comprise par les éditorialistes, les hommes politiques et les autorités religieuses. Ce défilé annuel très bien structuré est le plus imposant de l'histoire du Québec en termes de participation au cortège, à tout le moins jusqu'à la Deuxième Guerre mondiale. Après avoir connu une grande popularité, la participation des syndiqués s'effrite après la guerre, la célébration étant victime de changements dans la composition du membership syndical et touchée aussi par l'avènement de la société de consommation.

ABstract - In Canada and Quebec, the legal holiday of labour is observed the first Monday of September. Why did this feast hold on that date? There is nothing happening on that day dedicated to work and no organization or union commemorate or explain its meaning. In fact, the original sense of this holiday has been forgotten. But that day have been

1. Mes remerciements à Éric Leroux pour l'aide apportée à la recherche et au Conseil de recherche en sciences humaines pour le support financier. 
marked by an impressive parade of workers in Montreal for over fifty years (1886-1952). Organized by the international unions, the march brought together in an almost military order, thousands of unionized workers in the streets with banners, flags, several bands and floats dedicated to work. In occupying a public space, the unions wanted to assert on a symbolic way the dignity of their work, the strength of trade unionism and their identity as a social class. These meanings were shared also by the politicians, religious leaders and columnists of newspapers. This very well structured annual parade is the largest in the history of Quebec in terms of participation, at least until the Second World War.After experiencing great popularity, the involvement of unions crumbled after the Second World War, victim of a new wave of labour unions and harmed also by the spreading of consumer society.

E n Amérique du Nord, la fête légale du Travail est célébrée le premier lundi de septembre et non le $1^{\mathrm{er}}$ mai comme en Europe. C'est une journée chômée qui est encore l'occasion de manifestation de travailleurs et travailleuses dans certaines villes au Canada et aux États-Unis². Mais cette fête a perdu énormément de lustre au cours des dernières décennies et les démonstrations se font de plus en plus rares dans les villes en Amérique du Nord. Il fut pourtant une époque où des milliers de travailleurs et travailleuses syndiqués défilaient dans les rues de nombreuses villes pour marquer leur force et leur solidarité. Montréal était de ces villes où, pendant plusieurs décennies, les syndiqués ont voulu manifester la force du syndicalisme et illustrer l'affirmation de la classe ouvrière.

De nos jours, à Montréal comme dans les autres villes du Québec, rien ne vient marquer cette prétendue fête du premier lundi de septembre. Elle est une journée de congé chômée voulant commémorer le travail, mais elle a perdu toute sa signification originelle. Aucune organisation ne se manifeste pour la commémorer ou en expliquer la signification. Pour les centrales syndicales au Québec, le $1^{\mathrm{er}}$ mai représente la fête authentique des travailleurs et travailleuses à l'exemple de la fête internationale célébrée ailleurs qu'en Amérique du Nord. Le premier lundi de septembre est donc devenu une fête sans fête dont le sens est tombé dans l'oubli. Ayant perdu toute signification symbolique, ce jour s'est transformé en borne symbolique - peut-être pas pour longtemps encore - marquant la fin de l'été et des vacances et le début de l'automne avec la rentrée scolaire et le retour plein et entier au travail. C’est aussi une journée de congé

2. En septembre 2010, il y avait des défilés et pique-niques le jour de la fête du Travail, en Ontario, à Toronto, Hamilton et Windsor. Aux États-Unis, pour la première fois depuis 1882, il n’y a pas eu de défilé à New York le 9 septembre 2010. Cependant, il est maintenu à Détroit et dans d'autres villes à forte population de travailleurs salariés. 
bienvenue permettant un long week-end souvent marqué par des activités sportives ou encore une occasion de faire des emplettes.

Et pourtant, il n'y a pas si longtemps la fête du premier lundi de septembre était célébrée avec grand éclat par les syndicats montréalais affiliés aux unions internationales (d'origine états-unienne). Organisée par le Conseil des métiers et du travail de Montréal (CMTM) de 1886 à 1952, la fête avait comme élément central un défilé dans les rues de la ville. Cette célébration avait une ampleur considérable, dépassant toute autre manifestation publique à l'occasion d'une fête civique, y compris la fête des Canadiens français, le jour de la Saint-Jean-Baptiste ${ }^{3}$. C'était le défilé annuel structuré le plus imposant de l'histoire du Québec en termes de participation au cortège, à tout le moins jusqu'à la Deuxième Guerre mondiale.

En occupant collectivement un espace public, les syndiqués veulent manifester symboliquement la fierté de leur travail, la force du syndicalisme et leur identité comme classe sociale. C'est en ce sens aussi que la manifestation est comprise par les éditorialistes, les hommes politiques et les autorités religieuses. Bien avant la fameuse grève de l'amiante de 1949 et les années qui ont précédé la Révolution tranquille, elle illustre la vigueur de la «classe laborieuse» et le dynamisme du syndicalisme. Cette célébration reflète aussi l'importance du syndicalisme international et, à travers lui, l'influence sociale et culturelle des États-Unis sur le Québec.

Mais cette manifestation symbolique a connu un déclin à Montréal pour finalement disparaître à tel point que sa signification est maintenant tombée dans l'oubli. Cette fête, qui a mal résisté aux aléas du temps, représente une manifestation symbolique correspondant à des changements sociaux ancrés dans une période précise de l'histoire du Québec. Comme toute célébration symbolique, sa transmission n'est pas à l'abri du rejet, de la distorsion, de l'abandon et de l'oubli. C'est un bel exemple d'une fête institutionnalisée qui a connu un grand succès dans la première moitié du XX $\mathrm{XX}^{\mathrm{e}}$ siècle pour s'effacer dans la seconde. Comme nous le verrons, elle est victime de changement dans la composition du salariat et touchée aussi par l'avènement de la société de consommation.

Au début du $\mathrm{XX}^{\mathrm{e}}$ siècle, la ville de Montréal est l'une des grandes villes industrielles d'Amérique du Nord, au neuvième rang en fait selon la taille

3. Le défilé de la Saint-Jean-Baptiste à Montréal, qui a lieu au XIX ${ }^{e}$ siècle, n'est pas organisé chaque année avant que le 24 juin ne devienne fête légale en 1925. Le défilé de la fête du Travail suscite une participation supérieure jusqu’à la Deuxième Guerre mondiale selon un dépouillement des journaux effectué. 
de sa population en 1920. Elle est alors sans conteste la métropole financière, industrielle et commerciale du Canada avec une population atteignant un million d'habitants en 1931. C'est une ville à majorité francophone, pour les deux tiers de sa population environ, alors que les anglophones en représentent approximativement le quart ${ }^{4}$.

À cause de sa situation géographique, elle est largement soumise aux influences sociales et culturelles du continent nord-américain, dont celles du syndicalisme états-unien qui a dominé pendant longtemps le mouvement syndical canadien et québécois. À partir du milieu du XIX ${ }^{\mathrm{e}}$ siècle, des syndicats venus du Sud du $49^{\mathrm{e}}$ parallèle ont débordé au Canada et les unions auxquels ils sont rattachés commencent alors à joindre l'épithète internationale à leur nom. Jusqu'aux années 1930, ils ont comme caractéristique d'organiser les travailleurs selon le métier de leurs adhérents, ce qui permet un meilleur rapport de force avec les employeurs lorsque vient le temps de vouloir négocier des contrats collectifs de travail. Par la suite, certaines unions internationales ont réuni les travailleurs et travailleuses par usine indépendamment de leur tâche afin de pourvoir syndiquer les employés de la grande industrie manufacturière.

À Montréal, les syndicats internationaux sont très largement majoritaires : 10000 membres environ en 1901, 22000 en 1921, 30000 en 1931 et 50000 en $1940^{5}$. Pour les deux tiers environ, ce sont des francophones, très nombreux dans les syndicats de la construction, de l'imprimerie, de la chaussure et parmi les cheminots ${ }^{6}$. Cette proportion correspond d'ailleurs au leadership du CMTM $(73 \%)$ si on se fie à la consonance du patronyme des membres de la direction du Conseil de 1897 à 1930 ${ }^{7}$. On ne saurait donc assimiler le syndicalisme international à une institution étrangère à la société franco-québécoise. Mieux que toute autre institu-

4. Recensements du Canada dans Paul-André Linteau, Histoire de Montréal depuis la Confédération (Montréal, Boréal, 1991), 318.

5. Estimations à partir des effectifs des syndicats affiliés au Смтм auxquels il faut ajouter les membres des syndicats internationaux de cheminots qui demeurent indépendants du Conseil (Department of Labour, Labour Organizations in Canada, 1912, 129; 1921, 266; 1931, 244; 1940, 213).

6. Cette proportion est basée sur le patronyme du président et des membres du comité exécutif. Pour sa part, Alfred Charpentier, qui a fait partie du Syndicat international des briqueteurs et qui a bifurqué plus tard vers le syndicalisme catholique, estime la proportion de francophones dans les syndicats internationaux à $68 \%$ en 1918 et le compte rendu d'une assemblée du CMTM à $75 \%$ en 1931, Service des archives de la CSN, Compte rendu d'une journée sociale à la Villa Saint-Martin (avril 1918): 15 ; Le Monde Ouvrier, 17 janvier 1931, 1.

7. Bernard Dionne évalue à $60 \%$ la proportion des francophones parmi les dirigeants des syndicats internationaux montréalais de 1937 à 1957. Bernard Dionne, «Les Canadiens français et les syndicats internationaux. Le cas de la direction du Conseil des métiers et du travail de Montréal (1938-1958)", Revue d'histoire de l'Amérique française, 43,1 (été 1989): 53. 
tion, il incarne son américanité et l'influence exercée par les États-Unis sur la société francophone. Et parmi les valeurs qu'il transmet au Québec, il y a un événement symbolique majeur, la fête du Travail, célébrée le premier lundi de septembre avec autant d'enthousiasme à Montréal que dans les autres grandes villes nord-américaines. Elle y connaît même davantage de succès qu'ailleurs au Canada ${ }^{8}$.

Un premier défilé de la fête du Travail à Montréal est organisé le 6 septembre 1886 par l'Union des cigariers. Regroupés par syndicats dans un ordre rigoureux, 2000 travailleurs syndiqués défilent dans les principales rues du sud-est de la métropole avec deux fanfares et des bannières. Plusieurs maisons sont décorées de drapeaux et de nombreux spectateurs se pressent sur le parcours. Après le démantèlement du défilé au Champ de Mars, les familles des syndiqués sont transportées par bateau au parc Elmwood Grove pour un pique-nique, des jeux et des compétitions sportives amicales. En fin d'après-midi, une plateforme est érigée dans le parc où des orateurs se font entendre. L'initiateur de la fête à Montréal, George Warren, président de l'Union des cigariers et ex-organisateur des assemblées de Chevaliers du travail, y vante les mérites du syndicalisme, tandis que les deux candidats ouvriers aux prochaines élections provinciales, William Keys et W. Robertson, invitent les travailleurs à les appuyer ${ }^{9}$. On reprend ainsi à Montréal une célébration qui, dans les années 1880, se répand dans les grandes villes nord-américaines.

L'initiative de la fête du Travail vient des États-Unis après le succès d'un premier défilé à New York en 1882, alors que de 10000 à 20000 travailleurs syndiqués marchent dans les principales rues devant une foule estimée à 250000 personnes réparties le long du parcours. Défilant par syndicat dans un ordre presque militaire, ils arborent drapeaux, bannières et slogans inscrits sur des pancartes. Certains syndiqués portent leurs vêtements ou leurs outils de travail. Après quoi, ils sont invités avec leur famille à un pique-nique dans un parc de la ville où ils peuvent participer à des jeux, des compétitions sportives et s'adonner à une soirée dansante. La manifestation coïncide avec une rencontre de l'Assemblée générale de l'Ordre des Chevaliers du travail, organisation qui se porte à la défense

8. C'est ce que constate Craig Heron et Steve Penfold dans leur excellent ouvrage de synthèse sur la célébration de la fête du Travail au Canada, The Workers' Festival. A History of Labour Day in Canada (Toronto, University of Toronto Press, 2005), $340 \mathrm{p}$.

9. La Presse, 6 septembre 1886, 4; The Montreal Daily Star, 7 septembre 1886, 1 ; Jacques Rouillard, "Warren, George», Dictionnaire biographique du Canada, 1921-1930, vol. XV (Québec, Les Presses de l’Université Laval, 2005), 1172-1173. 
des travailleurs. L'idée de consacrer un jour de fête aux travailleurs serait venue de Peter J. McGuire, fondateur et secrétaire général de la Fraternité internationale des charpentiers et menuisiers, qui le propose à une réunion du Conseil central des métiers et du travail de New York ${ }^{10}$.

L'objectif consiste à consacrer une journée pour honorer les travaileurs syndiqués de la ville afin de montrer leur force et leur solidarité tout en voulant lancer un message aux politiciens pour qu'ils cessent de profiter des travailleurs ${ }^{11}$. On se rallie à un défilé au début de septembre puisque la fête "would come at the most pleasant season of the year, nearly midway between the Fourth of July and Thanksgiving, and would fill a wide gap in the chronology of legal holiday ${ }^{12}$ ». Ce n'est donc pas pour commémorer un événement marquant que cette journée est choisie, mais pour des raisons plus prosaïques: le temps est habituellement plaisant à New York au début septembre et le jour retenu se situe au milieu d'une longue période sans fête chômée.

Cependant, l'idée de faire défiler des travailleurs dans les rues n'est pas très originale pour l'époque. Au XIX ${ }^{\mathrm{e}}$ siècle, il arrivait souvent dans des villes nord-américaines, y compris à Montréal, de marquer par un défilé avec bannières et fanfares l'anniversaire d'un corps de métier. Des marches dans l'espace public avaient lieu également pour appuyer une réclamation particulière, recruter de nouveaux membres, etc. ${ }^{13}$. Au XIX ${ }^{e}$ siècle, le défilé sur les artères principales des villes apparaissait comme une importante forme de communication publique pour obtenir une reconnaissance sociale ou soutenir une cause ${ }^{14}$. Les groupes religieux, ethniques ou

10. Pour certains auteurs, Matthew Maguire, secrétaire du Conseil central des métiers et du travail de New York, serait l'initiateur de la Fête. Mais cette question apparaît très secondaire comme le fait remarquer Jonathan Grossman: «Like many ideas and institutions, it was created because its time had come. Because Labor Day met the needs of the age, many men participated in its development». Jonathan Grossman, «Who is the Father of Labor Day?», Labor History, 14,4 (automne 1973): 622 .

11. Michael Kazin et Steven J. Ross, "America's Labor Day: The Dilemma of a Workers' Celebration", The Journal of American History, 78,3 (mars 1992): 1302

12. New Yorker Volkszeitung, 19-20 mai 1882, dans S. Foner, From the Founding of the AFofL to the Emergence of American Imperialism (New York, International Publisher, 1975), 296-298.

13. C. Heron et S. Penfold, The Workers' Festival..., op. cit.; Eugene Forsey, Trade Unions in Canada, 1812-1902 (Toronto, University of Toronto Press, 1982), 10-13 ; Bryan D. Palmer, Working Class Experience (Toronto, McClelland and Stewart, 1992), 94-95).

14. Alan Gordon, Making Public Pasts: The Contested Terrain of Montréal's Public Memories, 18911930 (Montréal, McGill-Queen’s University Press, 2001), 233; Peter G. Goheen, «Parading: A Lively Tradition in Early Victorian Toronto,» dans Alan R. H. Baker et Gideon Biger, dir., Ideology and Landscape in Historical Perspective; Essays on the Meanings of Places in the Past (Cambridge, Cambridge University Press, 1992), 330-351; Peter G. Goheen, «Parades in Victorian Urban Canada», Urban History Review/Revue d'histoire urbaine, XVIII,3 (février 1990): 237-241; Susan G. Davis, Parades and 
sociaux organisaient aussi de telles manifestations. Dans le cas des travailleurs, on peut même faire remonter aux guildes du Moyen Âge l'habitude pour les ouvriers de métiers de manifester leur savoir-faire en arborant leurs outils et leur costume de travail ${ }^{15}$.

À Montréal, des défilés imposants de travailleurs ont précédé, à certaines occasions, la célébration de la fête du Travail. Dès 1867, les 8000 travailleurs de la Grande Association à Montréal défilent par corps de métier avec fanfares et drapeaux et portent à la boutonnière un ruban avec l'emblème de leur métier ${ }^{16}$. En 1881, des débardeurs montréalais en grève marchent dans les rues du port à deux reprises en juillet $1881^{17}$. La ville de Québec n'est pas en reste car un syndicat extrêmement vigoureux, la Société des journaliers de navires (débardeurs), organise un défilé le 23 juillet de 1867 à 1878 pour rappeler sa victoire contre les marchands et les arrimeurs lors d'une grève en 1866 . Entre 2500 à 5000 débardeurs participent à la marche avec bannières et fanfares ${ }^{18}$.

Au XIX siècle, le défilé de la Saint-Jean-Baptiste à Montréal est aussi l'occasion pour des syndicats de montrer leur savoir-faire et leur contribution à l'identité canadienne-française. Dès 1855, les typographes de l'Union typographique Jacques-Cartier défilent avec un char allégorique comportant une presse d'imprimerie ${ }^{19}$. De 1874 à 1899 , des syndicats sont présents lors du défilé du 24 juin pour souligner leur contribution au

Power. Street Theatre in Nineteenth Century Philadelphia (Philadelphia, Temple University Press), 116153 ; Ellen M. Litwicki, America's Public Holidays, 1865-1920 (Washington, Smithsonian Institution Press, 2000), 77-79; Sean Wilentz, "Artisan Republican Festivals and the Rise of Class Conflict in New York City, 1788-1837», dans M. H. Frisch et D. J. Walkowitz, dir., Working-Class America (Urbana, University of Illinois Press, 1983), 37-77.

15. Eric J. Hobsbawm, Worlds of Labour. Further Studies in the History of Labour (London, Weidenfeld and Nicolson, 1984), 76.

16. Jean Hamelin, "Médéric Lanctôt», Dictionnaire biographique du Canada, 1871-1880, vol. 10 (Québec, Les Presses de l’Université Laval, 1972), 465.

17. Jean Hamelin et al., Répertoire des grèves dans la province de Québec au XIX siècle (Montréal, Presses de l'École des Hec, 1970), 69. Les débardeurs de Montréal, encore dans les années 1940 et 1950, défilent en compagnie d'une fanfare dans le Vieux-Montréal, le troisième dimanche du mois de juin après une messe célébrée à l'église Notre-Dame-du-Bon-Secours. On veut marquer l'ouverture de la saison de navigation. En après-midi, les familles des débardeurs sont invitées à un piquenique à l'île Saint-Hélène. Nous ne savons pas quand cette célébration annuelle a pu débuter. Francis Gaudet, Vie syndicale et conditions de travail dans l'industrie du débardage à Montréal, 1946-1966: Étude du local 375 de l'Association internationale des débardeurs, mémoire de maîtrise (histoire), Université de Montréal, 1994, 47.

18. Peter C. Bischoff, Les débardeurs au port de Québec. Tableau des luttes syndicales, 1831-1902 (Montréal, Hurtubise, 2009), 157-160, 247-249, 310.

19. La Minerve, 28 juin 1855 ; Alan Gordon, op. cit., 148. 
progrès de la «nation ${ }^{20}$ ». Ainsi, en 1881 , les 200 membres du syndicat affilié à l'Union internationale des mouleurs déambulent dans les rues avec deux chars allégoriques illustrant leur métier. Le tout est suivi d'un pique-nique à l'île Grosbois auquel sont invitées les familles de travailleurs et la population en générale $e^{21}$.

Dans le cas de la célébration de New York le premier lundi de septembre en 1882, son originalité tient à ce que la fête vise à honorer le monde syndical et la classe ouvrière dans son ensemble et qu'elle est répétée chaque année par la suite. Tant aux États-Unis qu'au Canada, c'est la première fête qui soit célébrée un lundi et ce choix a probablement grandement contribué à la popularité de sa diffusion ${ }^{22}$. Le défilé de New York connaît un grand succès et le Conseil en recommande la célébration à d'autres conseils centraux pour en faire "a universal holiday for workingmen ». À son congrès de Chicago en 1884, la Federation of Organized Trades and Labor Unions, ancêtre de l'American Federation of Labor, adopte une résolution faisant du premier lundi de septembre la fête nationale des travailleurs et il en recommande l'observance à tous les salariés. L'idée fait rapidement tache d'huile puisqu'en 1889, la fête est célébrée dans 400 villes aux États-Unis ${ }^{23}$. Les syndicats pressent les villes, les États et le gouvernement fédéral de faire de cette journée une fête légale. Ils y parviennent dans plusieurs États et le président consent à ce qu'elle devienne une fête civique nationale en 1894.

Les syndicats au Canada, qui adoptent la fête dans les années 1880, invitent le gouvernement fédéral et les provinces à reconnaître ce jour comme fête légale pour honorer la classe ouvrière. Ainsi, les leaders syndicaux, témoignant devant la Commission royale d'enquête sur les relations de travail en 1886, de même que des résolutions adoptées par les délégués de syndicats au Congrès des métiers et du travail du Canada (CMTC) de 1888 à 1893 réclament que le gouvernement fédéral fasse du premier lundi

20. En 1899 , les syndicats internationaux suspendent leur participation au défilé parce que la constitution de la Société Saint-Jean-Baptiste, modifiée en 1874, rend très difficile pour des ouvriers d'occuper des fonctions de direction. Il fallait détenir une part de $100 \$$ dans le Monument national, somme qui n'était pas à la portée d'une bourse de travailleurs. Le reproche est périodiquement évoqué par les dirigeants de syndicats internationaux avant la Première Guerre mondiale. La Presse, 25 mai 1899, 9; La Patrie, 23 mai 1906, 3 , 10 juin 1907, 3; Michèle Guay, La Fête del Saint-Jean-Baptiste à Montréal, 1834-1909, mémoire de maîtrise (histoire), Université d’Ottawa, 1972, 51-285.

21. E. Forsey, op. cit., 252.

22. À remarquer que la première célébration a lieu un mardi, puis un mercredi. Ce n'est qu'à partir de 1884 que le lundi est adopté afin de profiter, à tout le moins, de deux jours de congé consécutif. Le samedi est un jour ouvrable à l'époque.

23. M. Kazin et S. J. Ross, op. cit., 1304. 
de septembre une fête légale au Canada ${ }^{24}$. Il acquiesce finalement en 1894, la même année que le gouvernement fédéral aux États-Unis. Le premier lundi de septembre devient ainsi un jour férié chômé, le premier consacré à un groupe social, et avant même que le gouvernement dédie une fête à des groupes ethniques (saint Patrick, saint George, saint Jean-Baptiste). Trois autres fêtes chômées non religieuses sont alors en vigueur au Canada: le Jour de l'An, le jour de la Confédération et la fête de la reine Victoria $^{25}$.

Pour sa part, le maire de Montréal en fait une fête civique en 1889 recommandant aux employeurs de fermer boutique pour la journée $e^{26}$. Effectivement, de très nombreuses entreprises et commerces observent déjà cette consigne, ce qui permet aux ouvriers de participer au défilé et aux spectateurs d'être plus nombreux sur le parcours ${ }^{27}$. Quant au gouvernement du Québec, il fait du premier lundi de septembre une fête légale en 1899. C'est à cette époque également que les commissions scolaires prennent l'habitude de retarder le début de la rentrée scolaire au lendemain de la fête du Travail ${ }^{28}$. Dans la ville de Québec, le Conseil central des métiers et du travail organise un défilé chaque année le premier lundi de septembre à partir de 1891 et l'exemple est suivi dans plusieurs autres municipalités du Québec. En 1907, la fête est aussi célébrée avec un défilé à Saint-Hyacinthe, Hull et Saint-Jean ${ }^{29}$.

24. E. Forsey, op. cit. 458; Fernand Harvey, Révolution industrielle et travailleurs. Une enquête sur les rapports entre le capital et le travail au Québec à la fin du $19^{e}$ siècle (Montréal, Boréal Express, 1978), 244, 319.

25. Statues of Canada, 1872, 33; 1879, $305 ; 1887,4 ; 1893,107$, dans Craig Heron et Steve Penfold, "The Craftmen's Spectacle : Labour Day Parades in Canada, the Early Years», Histoire sociale/Social History, XXIX,58 (novembre 1996): 359.

26. La Presse, 29 août 1889, 4. En 1898, le Conseil fédéré réclame du maire qu’il fasse du premier lundi de septembre une fête civile, ce qui en ferait une fête obligatoirement chômée (Procès-verbal de l'assemblée du Conseil fédéré de métiers et du travail, 4 août 1898, 40, Service des archives et de gestion de documents de l'UQAM, Fonds du CMTM (103P-162). Ce fonds d'archives est très incomplet; il renferme les procès-verbaux des réunions de l'assemblée ou du comité exécutif uniquement pour certaines années. Par ailleurs, ces procès-verbaux demeurent très laconiques, se contentant de rendre compte des résolutions adoptées; il y a très peu d'informations concernant le comité de la fête du Travail. Plus riches de renseignements sont les comptes rendus des réunions par les quotidiens de Montréal et Le Monde ouvrier, organe des syndicats internationaux.

27. Les banques, les bureaux publics et presque toutes les manufactures et grands établissements sont fermés en 1894, Le Monde, 4 septembre 1894, 1.

28. The Montreal Daily Star, 29 août 1889, 4; La Presse, 29 août 1895, 1. Peu d'écoles continuent d'ouvrir leurs portes en 1905, le CMTM faisant des efforts pour que tous les élèves aient congé. Procès-verbal du Comité exécutif du CMTM, 22 avril 1909, 116, UQAM, Services des archives et de gestion de documents, Fonds du CMTM (103P-162).

29. La Presse, 31 août 1907, 5. 
La célébration du premier lundi de septembre, qui se répand dans les villes canadiennes à partir de 1883 , est donc à l'origine de l'actuelle fête du Travail ${ }^{30}$. Elle se situe dans le courant nord-américain de célébration qui a prévalu à la suite du défilé de New York en 1882. Trois raisons s'imposent pour le reconnaître: le CMTC, principal organisme représentant les travailleurs canadiens, a réclamé que le premier lundi de septembre devienne fête nationale; elle est célébrée par la suite à chaque année à la même date en hommage aux travailleurs salariés canadiens. Enfin, lorsqu'ils veulent tracer l'origine de la fête du Travail, les leaders syndicaux et les journaux montréalais font référence à la célébration de New York en 1882.

\section{LE DÉFILÉ À MONTRÉAL}

Nous l'avons vu, la première fête du Travail à Montréal est organisée en 1886 à l'instigation de l'Union des cigariers. Trois ans plus tard, elle en cède l'organisation au Conseil central des métiers et du travail de Montréal. Fondé le 12 janvier 1886, le Conseil central regroupe alors des syndicats internationaux et des assemblées de Chevalier du travail. Son rôle politique consiste à faire connaître le mouvement syndical et à acheminer des réclamations auprès des pouvoirs publics, principalement vers le Conseil de ville de Montréal. En 1897, le Conseil se fractionne lorsque la plupart des syndicats internationaux le quittent pour former le Conseil des métiers fédérés et du travail de Montréal. Ces derniers reprochent au Conseil central d'accorder aux assemblées un même nombre de délégués aux assemblées des Chevaliers qu'aux syndicats internationaux qui comptent habituellement beaucoup plus de membres ${ }^{31}$.

Cette division se transporte dans les rues de Montréal: chaque conseil organise des défilés de la fête du Travail parallèles de 1898 à 1907. Avec

30. Il arrive parfois qu'on veuille faire commencer cette célébration au Canada à partir des défilés de travailleurs à Toronto le 15 avril 1872 ou le 22 juillet 1882, initiative qui est reprise à Hamilton et Oshawa en 1883. Dans le cas de Toronto, on invoque que Peter J. McGuire, initiateur de la fête à New York, était un orateur invité au défilé et qu’il aurait eu en mémoire cet événement pour le suggérer au Conseil central des métiers et du travail de New York. Mais ce dernier ne serait pas venu à Toronto à cause de la maladie de sa femme, The Globe, 16 avril 1872, 1; 24 juillet 1882, 6; C. Heron et S. Penfold, The Workers' Festival..., op. cit., 33-36; «The Origins of Labour Day », The Canadian Encyclopedia (Toronto, McClelland and Stewart, 1999), 1266; Wikipedia, Labour Day, http:/ / en.wikipedia.org/wiki/Labour_Day; Clifford A. Scotton, "The Origin of Labour Day», Canadian Labour (septembre 1961): 39; «Highlights in Canadian labour history », CBC News, Canada Union Movement, www.cbc.ca/canada/story/2009/09/04/f-labour-day-canadian-workforce.html.

31. Jacques Rouillard, Les syndicats nationaux au Québec de 1900 à 1930 (Québec, Les Presses de l’Université Laval, 1979), 50-54, 71-72. 


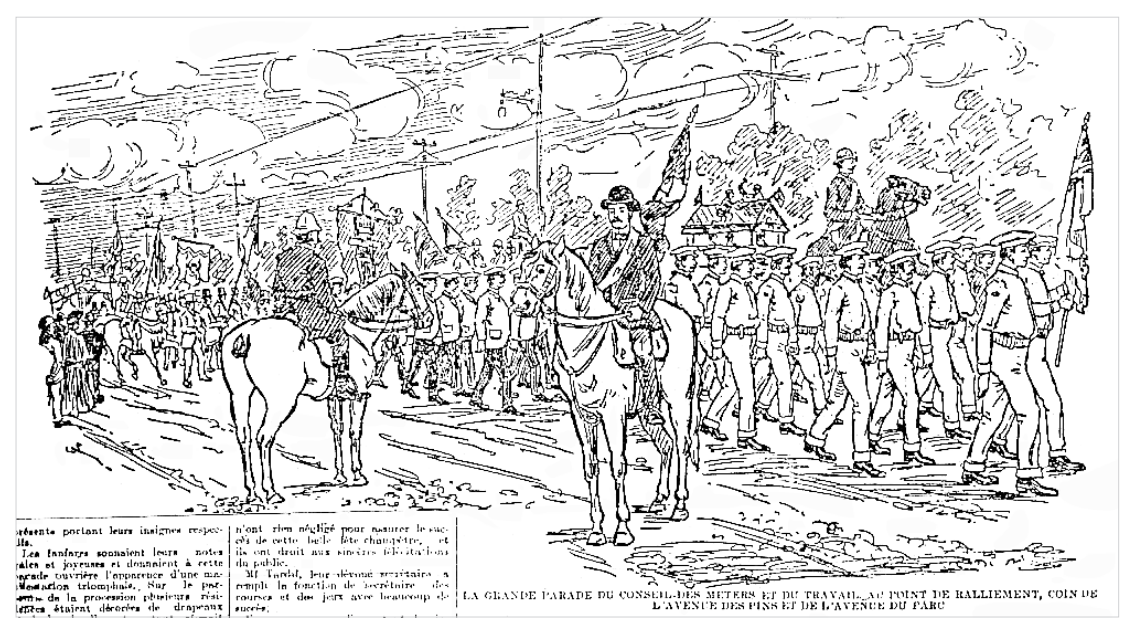

Départ du défilé du 5 septembre 1904 à l'angle de l'avenue des Pins et de l'avenue du Parc Source: La Patrie, 6 septembre 1904, 1.

l'augmentation importante du nombre de syndicats internationaux à Montréal, le Conseil fédéré supplante rapidement le Conseil central. Ce dernier annule son défilé à partir de 1908 pour ne conserver qu'une fête champêtre dans un parc, manifestation qui perdure jusqu'en $1915^{32}$. Le Conseil fédéré devient en 1903 le Conseil des métiers et du travail de Montréal (CMTM) tandis que le Conseil central adopte le nom de Conseil central national des métiers et du travail de Montréal.

La forte croissance du syndicalisme international à Montréal dans la première moitié du $\mathrm{xx}^{\mathrm{e}}$ siècle donne rapidement une envergure considérable au défilé du CMTM. Détenant une charte de l'American Federation of Labor, le Conseil représente un organisme central pour les syndicats internationaux afin de faire connaître leur mouvement et défendre les intérêts des syndiqués et des travailleurs en général. Le préambule de sa constitution de 1897 précise qu'il a pour but «d'organiser et d'unir les classes ouvrières pour leur protection mutuelle, leur éducation et leur avancement social ${ }^{33}$ ").

Outre un travail d'éducation des syndiqués et de la population en général, sa principale tâche consiste à adopter des résolutions destinées

32. Le Conseil central des unions canadiennes de Montréal affilié à la Fédération canadienne du travail organise un défilé parallèle de 1923 à 1925 qui comprend moins de dix syndicats.

33. Procès-verbal de l'assemblée du Conseil fédéré de métiers et du travail, 28 juillet 1897, 19 août 1897, Service des archives et de gestion de documents de l'UQAM, Fonds du CMTM (103P-162); La Patrie, 2 septembre 1899, 9. 


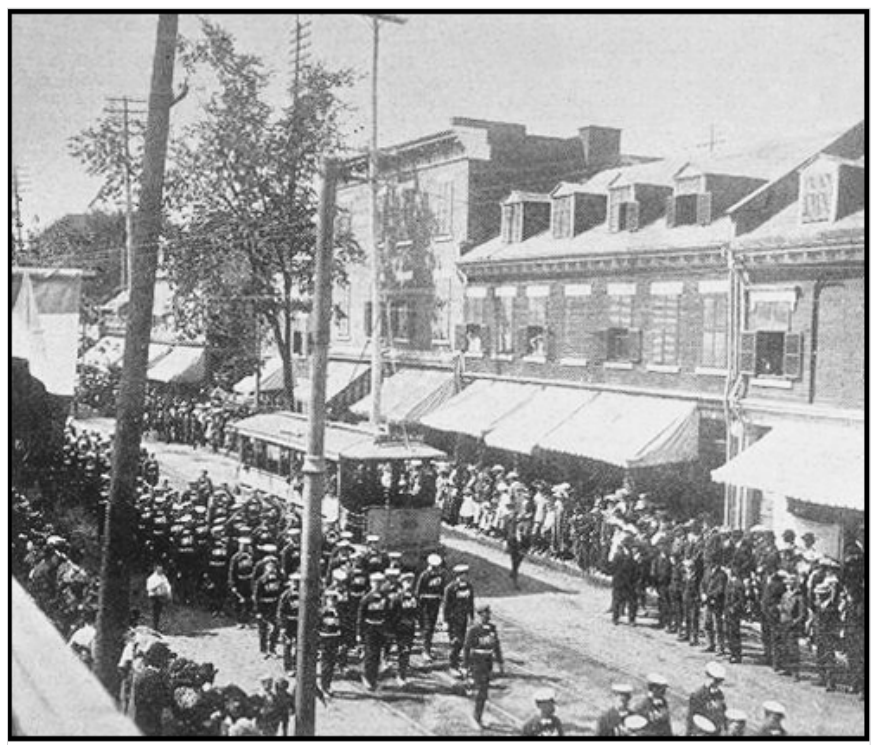

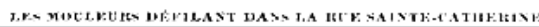

Défilé, rue Sainte-Catherine, des membres du syndicat, local no 21 , de l'Union internationale des mouleurs d'Amérique du Nord Source: L'Album universel, vol. 20, 73, 445, 12 septembre 1903.

aux organismes municipaux, notamment le Conseil de ville de Montréal. Les délégués votent également des résolutions pour qu’elles soient débattues aux assemblées annuelles du Congrès des métiers et du Travail du Canada et acheminées par la suite au gouvernement d'Ottawa et de Québec. De ses revendications se dégage un projet de société proche de celui qui anime de nos jours le syndicalisme et que nous caractériserons de social-démocrate ${ }^{34}$. Les réunions bimensuelles du Conseil, dont rendent compte les grands quotidiens, attirent en moyenne une centaine de délégués de syndicats. Des comités permanents se greffent aux activités du Conseil dont celui de la fête du Travail qui supervise l'organisation du défilé et de la fête champêtre pour les familles des syndiqués.

Organisé avec soin, le défilé, très bien structuré, s'effectue dans un ordre rigoureux, presque militaire, selon le modèle des marches dans les autres villes nord-américaines. Les syndiqués sont regroupés par syndicat avec

34. Voir Jacques Rouillard, «Le Conseil des métiers et du travail de Montréal. Aux origines de la social-démocratie québécoise, 1897-1920 ", dans Jacques Rouillard, L'expérience syndicale au Québec (Montréal, VLB éditeur, 2008), 111-135. 
une place précise pour chacun d'eux ${ }^{35}$. Seuls les membres des syndicats approuvés par le comité d'organisation défilent dans les rues pendant au moins une heure et demie. Il y a donc une séparation nette entre les acteurs du défilé et les spectateurs qui sont très nombreux le long du parcours.

Comme le montre le tableau 1 (p. 46-47), le cortège des syndiqués prend véritablement son envol au début du siècle avec une participation oscillant entre 10000 et 20000 travailleurs $^{36}$. C'est l'époque où certains syndicats imposent même une amende de 1 \$ à 3 \$ aux syndiqués qui ne participent pas au défilé ${ }^{37}$. Contrairement aux États-Unis et dans plusieurs villes au Canada, il n'y a pas de baisse de la participation des syndiqués à la manifestation avant et après la Première Guerre mondiale ${ }^{38}$. Parfois même, particulièrement de 1918 à 1925, années de fort militantisme, on compte entre 25000 et 30000 syndiqués qui déambulent dans les rues.

C'est par la suite que les marcheurs se font moins nombreux, même si les syndicats affiliés au CMTM comptent des effectifs plus substantiels. Les dirigeants syndicaux commencent alors à faire appel au sens du devoir des syndiqués pour qu'ils se joignent au défilé. Il n'en reste pas moins que le cortège comprend souvent entre 15000 et 20000 syndiqués de 1929 à 1942 lorsque le temps est clément. Après la Deuxième Guerre mondiale, la participation s'étiole pour des raisons que nous verrons plus bas.

Quant à la foule le long du parcours, elle atteint un nombre impressionnant de spectateurs selon le compte rendu des journaux. C'est entre 100000 et 200000 personnes qui se massent sur les trottoirs par beau temps. Compte tenu de la population de Montréal et de sa banlieue, c'est le tiers des habitants qui assistent au défilé. Et nombreuses sont les maisons qui sont décorées le long du parcours et où flottent des bannières et des drapeaux patriotiques (Union Jack britannique, Red Enseign, tricolore français). C’est un événement marquant de la vie publique des Montréalais.

Le défilé est organisé avec soin par le Comité de la fête du Travail qui obtient parfois un appui financier de la ville de Montréal. Faire défiler des

35. L'organisation du défilé à Montréal rejoint le modèle des marches dans les autres villes canadiennes. G. Heron et S. Penfold, The Workers' Festival..., op. cit., 41-79; «The Craftmen's Spectacle... ", Histoire sociale/Social History, XXIX,58 (novembre 1996):357-389.

36. Les syndicats appartenant aux unions internationales de cheminots, qui sont nombreux à Montréal (27 syndicats en 1921), ne font pas partie du CMTM et, sauf quelques exceptions, ne participent pas au défilé.

37. La Presse, 2 septembre 1904; Le Monde Ouvrier, 3 septembre 1948, 1.

38. C. Heron et S. Penfold, The Workers' Festival..., op. cit., 144-145; M. Kazin et S. J. Ross, op. cit., 1313-1315. 
Tableau I

Participation et assistance au défilé de la fête du Travail à Montréal

\begin{tabular}{|c|c|c|c|}
\hline Année & Participants aux défilés & Effectifs du CMTM & Estimation de la foule \\
\hline 1886 & 2330 & & \\
\hline 1888 & 8000 & & \\
\hline 1889 & 9000 & & \\
\hline 1892 & 7000 & & \\
\hline 1899 & 10000 & & \\
\hline 1900 & 5000 & & 20000 \\
\hline 1901 & 10000 & & 50000 \\
\hline 1902 & 20000 & & \\
\hline 1903 & 20000 & & \\
\hline 1904 & 20000 & & 100000 \\
\hline 1905 & 20000 & & \\
\hline 1906 & 10000 & & \\
\hline 1907 & 18000 & & \\
\hline 1908 & 20000 & & 100000 \\
\hline 1910 & 10000 & & 150000 \\
\hline 1911 & 20000 & & 150000 \\
\hline 1912 & 20000 & 25000 & \\
\hline 1913 & 10000 & 35000 & 100000 \\
\hline 1914 & 18000 & 30000 & \\
\hline 1915 & & 12000 & 250000 \\
\hline 1916 & & 21000 & \\
\hline 1917 & & 25000 & \\
\hline 1918 & 30000 & 27000 & \\
\hline 1919 & 30000 & 55000 & \\
\hline 1920 & 25000 & 40000 & \\
\hline 1921 & 30000 & 22000 & \\
\hline 1922 & 25000 & 35000 & 100000 \\
\hline 1923 & & 45000 & \\
\hline 1924 & 30000 & 38000 & \\
\hline 1925 & 30000 & 39000 & \\
\hline 1926 & & 37000 & \\
\hline 1927 & & 39000 & \\
\hline 1928 & 10000 & 37500 & \\
\hline 1929 & 16000 & 40000 & \\
\hline 1930 & 22000 & 41700 & \\
\hline
\end{tabular}




\begin{tabular}{|c|c|c|c|}
\hline 1931 & 10000 & 42000 & \\
\hline 1932 & 20000 & 42140 & 150000 \\
\hline 1933 & 20000 & 43700 & \\
\hline 1934 & & 45250 & \\
\hline 1935 & 5000 & 47000 & 50000 \\
\hline 1936 & 6000 & 40000 & \\
\hline 1937 & 15000 & 36652 & 50000 \\
\hline 1938 & 15000 & 37128 & 50000 \\
\hline 1939 & 17000 & 37604 & \\
\hline 1940 & & 37604 & \\
\hline 1941 & 14000 & 47124 & \\
\hline 1942 & 20000 & 47600 & \\
\hline 1943 & 12000 & 67471 & \\
\hline 1944 & & 61560 & \\
\hline 1945 & & 64444 & 200000 \\
\hline 1946 & & 67260 & \\
\hline 1947 & 5000 & 60997 & \\
\hline 1948 & 3500 & 70110 & \\
\hline 1949 & & 74309 & \\
\hline 1950 & & 74670 & \\
\hline 1951 & 3000 & 74118 & \\
\hline
\end{tabular}

Moyenne des estimations des participants et de la foule se massant le long du parcours selon trois quotidiens montréalais lorsqu'ils en font mention (La Presse, La Patrie, The Montreal Daily Star). Pour 1899, 1902, 1903, 1904 et 1905, la moyenne est établie selon la participation aux défilés des syndicats affiliés au Conseil fédéré et au Conseil central. Les estimations n’ont évidemment rien de scientifique. Il arrive parfois que la pluie réduise substantiellement la participation des travailleurs et le nombre de spectateurs. Les effectifs du CMTM de 1912 à 1936 proviennent des déclarations fournies par le secrétaire du Conseil au ministère fédéral $\mathrm{du}$ Travail; elles ne sont pas toujours fiables, mais elles offrent un ordre de grandeur (Organisations ouvrières au Canada [Ottawa, ministère du Travail], 1912-1951). Les données de 1937 à 1951 sont tirées des estimations mieux fondées de Bernard Dionne (Les «unions internationales " et le Conseil des métiers et du travail de Montréal, 1938 à 1958, vol. 1, thèse de doctorat [histoire], Université du Québec à Montréal, 1988, 275).

milliers de travailleurs de façon ordonnée dans les rues nécessite une organisation méticuleuse et une préparation de plusieurs mois. Les journaux font connaître la place précise assignée à chaque syndicat. Un commissaire ordonnateur à cheval avec des adjoints assure le bon déroulement du cortège. Des policiers, parfois à cheval, ouvrent la marche. Les syndiqués déambulent parés de leurs plus beaux habits (souvent redingote noire avec chapeau), le plastron enrubanné d'insignes et de boutons à l'emblème 


\section{LA FETE DU TRAVAIL}

Malgré la pluie, les ouvriers de Montréal la célębrent avec

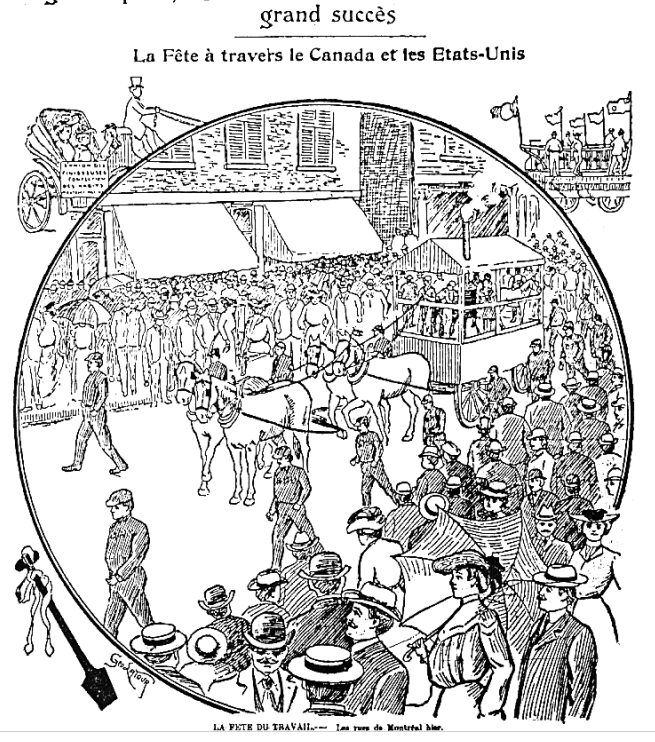

Char allégorique du syndicat, local $\mathrm{n}^{\circ} 134$, de la Fraternité internationale des chaudronniers d'Amérique du Nord Source: La Patrie, 2 septembre 1902, 2.

de leur syndicat. Certains portent avec fierté leurs vêtements de travail: par exemple, les plâtriers en costume blanc, les peintres aussi en blanc avec casquettes et gants blancs, les ferblantiers en salopette bleue et les mouleurs avec un pantalon noir et un chandail portant le sigle IMU (Iron Moulder Union), etc. Les femmes feront partie du défilé à partir de 1902; elles sont plus nombreuses à mesure que sont formés des syndicats féminins, notamment à la fin des années 1930 .

Les membres de l'exécutif des syndicats défilent à pied en fin de cortège, d'abord en carrosse tiré par des chevaux et, plus tard, en automobile. Ils sont accompagnés de personnalités politiques invitées, provenant de la ville de Montréal, du gouvernement du Québec et d'Ottawa. Le maire de Montréal participe presque toujours au défilé tout comme des échevins, députés et ministres, parfois même le premier ministre du Québec. Les dirigeants syndicaux font parvenir un message de circonstance à la population qui est reproduit textuellement dans les journaux à partir des années 1930. Le CMTM publie un programme souvenir commémorant la fête du Travail.

Afin de donner un air de festivité à la marche, plusieurs fanfares accompagnent le défilé (22 fanfares en 1919) et la plupart des syndicats affichent 
des bannières de soie à l'emblème de l'union internationale à laquelle ils sont affiliés. Des affiches mettent souvent en relief des réclamations syndicales comme: "Engagez le travail honnête», "Suppress the work of children $^{39}$ ", «L'Union fait la force ${ }^{40}$ ", «À bas les monopoles ${ }^{41}$ » «À bas les trous infects où on fait un travail de mercenaire et misérable $e^{42}$ », «Pas de scabs $^{43}$ », «En grève depuis 25 semaines et toujours solides ${ }^{44}$ », «La semaine de travail de 44 heures », "Vacances payées ${ }^{45}$ ».

Plusieurs chars allégoriques illustrant le métier des syndiqués font aussi partie de la manifestation. Les travailleurs veulent montrer qu'ils sont fiers de la pratique de leur métier. Ainsi des menuisiers s'occupent à construire portes et cadres de fenêtre sur un char ou encore des tailleurs de pierre découpent un gros bloc de pierre. En 1927, parmi les nombreux chars allégoriques, l'un d'entre eux montre deux vieux cordonniers travaillant sur un petit banc en contraste avec les machines modernes moins fatigantes pour les travailleurs, un autre expose des appareils électriques modernes tandis qu'un tramway datant de 1892 tiré par deux chevaux est suivi par un tout nouvel autobus transportant 95 employés $^{46}$. En 1950, des machinistes réparent un moteur d'avion monté sur un camion, un soudeur et un riveteur travaillent sur un immense réservoir installé sur une plate-forme d'un camion tandis que, sur un autre char allégorique, la reine des midinettes est assise sous un immense rouleau de fil en compagnie de travailleuses lançant aux spectateurs des bouts de galons à mesurer ${ }^{47}$.

Pour inciter les syndicats à réaliser un char allégorique, un prix est attribué à partir de 1917 au syndicat qui présente le plus beau char en tenant compte aussi du nombre de syndiqués et de leur tenue vestimentaire. Plus tard, le journal La Presse patronne ce prix accompagné d'une coupe en argent $t^{48}$. Des employeurs sont tentés de contribuer financièrement à la réalisation de chars allégoriques tant pour manifester leur appui à leurs employés que pour faire connaître leur marque de commerce. Une première requête est faite en ce sens au Conseil en 1935. Le comité d'or-

39. La Presse, 3 septembre 1888, 2 .

40. La Presse, 2 septembre 1890, 3.

41. La Patrie, 6 septembre 1892, 4.

42. La Presse, 4 septembre 1900, 1.

43. La Presse, 8 septembre 1908, 5 .

44. La Presse, 8 septembre 1925, 10.

45. Le Monde Ouvrier, septembre 1946, 2.

46. Le Monde Ouvrier, 10 septembre 1927, 2.

47. La Presse, 5 septembre 1950, 22.

48. La Presse, 3 août 1917, 6; Le Monde Ouvrier, 17 août 1929, 1. 
ganisation de la fête accepte qu'une entreprise contribue à la réalisation d'un char allégorique, sous réserve qu'il n'y ait pas d'annonce sauf une plaque avec le nom de l'entreprise ${ }^{49}$. Plus tard, après la Deuxième Guerre mondiale, cette plaque se transforme sur certains chars allégoriques en marque de commerce bien en évidence comme c'est le cas également dans plusieurs autres villes canadiennes ${ }^{50}$.

Le parcours du défilé est révélateur de l'importance qu'on veut lui accorder. Les premiers défilés se tiennent dans les rues commerciales de l'est de Montréal depuis le Champs-de-Mars (arrière de l'Hôtel de ville actuel). À partir de 1889, le défilé se déplace davantage vers l'ouest de la ville en empruntant les artères du centre financier de Montréal (rues Saint-Jacques et McGill) pour revenir dans l'est dans les rues SainteCatherine et Saint-Laurent jusqu'au parc de l'Exposition (rue MontRoyal). De 1906 à 1934, le cortège abandonne le quartier des affaires pour se concentrer davantage dans les rues commerciales. Depuis le carré Viger, les syndiqués empruntent le parcours formé principalement des rues Saint-Denis, Sainte-Catherine, Saint-Laurent, Ontario et Amherst pour terminer au carré Papineau. Ce sont des rues de quartiers ouvriers plus susceptibles d'attirer des spectateurs avec un lieu de démembrement proche du populaire parc d'amusements Dominion. De 1934 à 1952, le défilé débute au parc Lafontaine et se termine au carré Viger en empruntant notamment les rues Sherbrooke, Papineau, Sainte-Catherine, SaintLaurent et Craig (maintenant rue Saint-Antoine).

Après le défilé, la célébration se poursuit par une fête champêtre pour les ouvriers et leur famille dans un des grands parcs à la périphérie de la métropole ou encore dans un populaire parc d'attractions privé. Ce sont les parcs Sohmer au début du siècle (aujourd'hui derrière la maison de Radio-Canada), Dominion (situé entre le fleuve et la rue Notre-Dame) dans les années 1920 et 1930 et Belmont (Cartierville) pendant et après la Deuxième Guerre mondiale. Des jeux et des activités sportives sont prévus tant pour les syndiqués que pour leur famille: courses, lancée du poids, jeux d'adresse, souque à la corde, etc. Des prix sont remis aux gagnants. Il peut aussi arriver qu'un banquet réunisse les principaux dirigeants syndicaux suivi d'une soirée dansante et d'un feu d'artifice. C'est l'occasion donc de fraterniser et de manifester une solidarité entre familles ouvrières.

49. La Presse, 10 août $1935,52$.

50. G. Heron et S. Penfold, The Workers' Festival..., op. cit., 205-219. 
Pour donner une plus juste idée du caractère de la manifestation, arrêtons-nous à l'année 1914, date du $25^{\mathrm{e}}$ anniversaire de l'organisation de la fête $^{51}$. Le ralliement des syndicats internationaux a lieu cette année-là place Viger. Le défilé, qui s'ébranle à 9h30, compte 67 syndicats de métier, 12 fanfares qui jouent les hymnes nationaux, une dizaine de chars allégoriques, un nombre "infini» de drapeaux et de bannières aux couleurs canadiennes, anglaises, françaises, belges et américaines. La foule des spectateurs massés des deux côtés de la rue observe et applaudit au passage de ces travailleurs dont le nombre est évalué entre 15000 et 20000.

Les membres de plusieurs syndicats portent avec fierté leurs vêtements de travail: les plâtriers en costume blanc, les ferblantiers en salopette bleue avec leur casque en fer blanc, les métallurgistes en tricot rouge, les mouleurs avec leur pelle sur l'épaule, les souffleurs de verre portant à la main une canne en verre et les cigariers portent aux lèvres un cigare de choix. Le char allégorique du syndicat des ingénieurs stationnaires fait voir une machine à vapeur en action; un autre, celui des débardeurs, représente un navire en chargement; un troisième illustre la construction métallique; et un autre, celui des tailleurs de pierre, fait entendre un air connu grâce aux coups de boucharde sur une immense galette de pierre. Pour sa part, l'Union des employés civiques est escortée par plus de cinquante cavaliers.

Le maire de la ville, Médéric Martin, escorté d'un détachement de constables et de pompiers en grande tenue, marche dans les rangs de l'Union des cigariers, dont il est membre. L'exécutif du Conseil des métiers et ses invités ferment le cortège. En après-midi, un pique-nique pour les familles ouvrières a lieu au Parc Dominion où un programme de jeux est prévu pour les enfants et les adultes. Des prix sont accordés aux gagnants. Les journaux rendent compte le lendemain des noms des vainqueurs. Dans leur compte rendu de la fête, le journal The Montreal Daily Star titre: "Record of Labor Best in History; Parade Monday"; et La Presse: "La Fête du travail chômée avec éclat. Une manifestation grandiose", célébrée, selon le journaliste, "avec tout l'éclat et le succès accoutumé».

En 1919, au faîte de la participation syndicale, le défilé, qui «n’avait jamais revêtu un caractère aussi grandiose» selon La Patrie, compte 30000 ouvriers membres de 125 syndicats marchant pendant deux heures. Ils

51. La Presse, 8 septembre 1914, 2; La Patrie, 8 septembre 1914, 4; The Montreal Daily Star, 5 septembre, 28 . 
sont accompagnés de 22 corps de musiciens et d'une quarantaine de voitures ou chars allégoriques où flottent des centaines de bannières et de drapeaux $^{52}$. Sur le parcours, les maisons sont décorées, et des milliers de personnes sur les trottoirs applaudissent les participants. Le défilé est si imposant que le syndicat en tête du défilé a atteint le point de rupture de la parade au carré Papineau alors que le dernier syndicat n'est pas encore parti du point de ralliement au carré Viger. Le président du CMTM, John T. Foster, évoque dans son message que

la fête du Travail était un jour de réjouissance, et que (la classe ouvrière) ne devait pas craindre de manifester sa force, et qu'elle doit être fière du progrès accompli cette année par le travail organisé. Les classes laborieuses dormaient, elles se sont réveillées aux idées nouvelles de liberté. Le désir de jouir de la vie est devenu son cri de ralliement. Le prolétariat reprend conscience de sa force ${ }^{53}$.

\section{SIGNIFICATION SYNDICALE DE LA FÊTE}

Une fête doit être marquée par le désir de rompre avec la routine du quotidien dans une atmosphère de joie et d'allégresse. Son sens original comporte la notion que «la fête ne se donne pas en représentation, mais qu'elle se $v^{1} t^{54}$ ». La fête du premier lundi de septembre correspond pleinement à cette définition car elle se vit collectivement dans l'important défilé auquel les travailleurs participent en déambulant dans les rues. Ils deviennent eux-mêmes des acteurs de la démonstration et non de simples spectateurs. Le défilé se distingue ainsi de ceux de la Saint-Jean-Baptiste et de la Saint-Patrick à Montréal ou encore des défilés marquant la fête du Canada.

Par ailleurs, l'objectif de la célébration ne consiste pas uniquement à se réjouir et à se divertir. Au-delà des festivités, les organisateurs veulent donner à la fête une signification précise. Elle n'est pas un rappel à contenu historique comme le Memorial Day aux États-Unis ou le Victoria Day au Canada anglais. Elle ne commémore pas non plus un douloureux épisode lié à l'histoire des travailleurs comme le jour du $1^{\mathrm{er}}$ mai. C'est plutôt une fête qui vise à rappeler l'appartenance à une entité collective, mais pas au même titre que les fêtes nationales où on se réjouit d'être

52. La Patrie, 2 septembre 1919, 1; La Presse, 2 septembre 1919, 10; Le Monde Ouvrier, 6 septembre $1919,1$.

53. La Patrie, 29 août $1919,7$.

54. Jean-Marc Savary, «La Fête, cette hantise», Autrement, 7/76, 168, dans La Fête, pratique et discours (Paris, Annales littéraires de l’Université de Besançon, 1981), 5. 
canadiens-français, québécois ou canadiens. La fête du Travail invite à célébrer une identité sociale, celle des travailleurs salariés, une classe sociale en pleine expansion à la fin du XIX ${ }^{\mathrm{e}}$ siècle. L'éditorialiste du journal La Presse le réalise dès 1888 :

Oui, la fête du travail n'est pas une simple démonstration qui doit être un jour de repos après une année de labeur; mais c'est l'affirmation solennelle d'un corps important qui vient affirmer sa puissance et reconnaître publiquement ses obligations, avec toute la dignité qui convient à la noblesse et à la grandeur du travail ${ }^{55}$.

La première célébration à Montréal en 1886 survient précisément au moment où les tra-

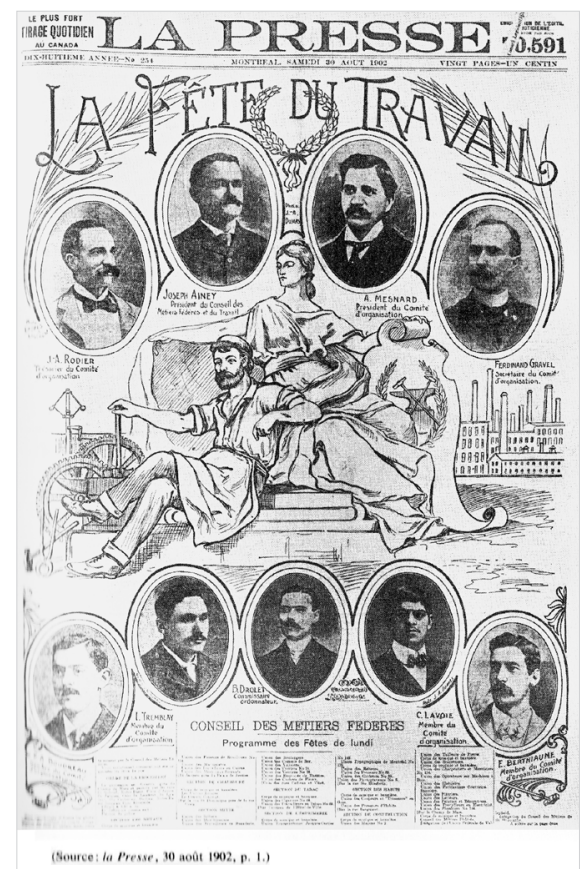

Le journal La Presse consacre souvent sa une à promouvoir la fête du Travail

Source: La Presse, 30 août 1902, 1.

vailleurs syndiqués veulent étendre leur influence au niveau politique. Le Conseil central des métiers et du travail de Montréal, formé la même année, a pour rôle principal de se faire l'interprète de la classe ouvrière. L'organisme veut manifester la présence de cette classe ouvrière de manière symbolique en occupant l'espace public par un défilé annuel grandiose. Il veut illustrer l'importance et le pouvoir des travailleurs salariés tout comme la légitimité du syndicalisme, une organisation encore largement contestée par les employeurs à cette époque. À travers cette manifestation de solidarité, les syndiqués affirment leur contribution essentielle au développement de la société et leur désir aussi d'obtenir une reconnaissance sociale.

Même si la célébration se situe dans un cadre institutionnel sans volonté de contestation radicale de l'ordre social, l'occupation de la rue représente "an assertion of power", "an annual assertion of class presence", "a symbolic assertion of the fundamental power of workers ». Cette expli- 
cation de l'historien Eric J. Hobsbawm pour le défilé du $1^{\mathrm{er}}$ mai en Europe convient aussi au premier lundi de septembre à Montréal. Les syndiqués veulent affirmer symboliquement l'existence des travailleurs salariés comme classe sociale et leur contribution au développement de la société. «Pourquoi célébrer la fête du travail?» demande le leader ouvrier Gustave Francq en 1932:

le jour choisi par le Travail Organisé - choix ratifié par la suite par les gouvernements du Canada et des États-Unis - pour glorifier le rôle joué dans la société par la classe ouvrière, pour reconnaître la part importante qu'elle prend dans la marche en avant du progrès et de la civilisation, journée qui lui permet de démontrer au public sa force numérique, son énergie et sa solidarités6.

C'est le sens aussi qui ressort des messages publics diffusés chaque année aux travailleurs et à la population en général par les dirigeants syndicaux (le procédé s'institutionnalise dans les années 1930) ${ }^{57}$. Désireux de souligner la solidarité des "masses laborieuses», ils s'appliquent aussi à affirmer sa puissance aux employeurs et à la classe politique. C'est ce que rappelle, en 1917, Edmond Clermont, président du syndicat montréalais de l'Union internationale des cigariers:

À la veille de la fête du Travail, il est de mon devoir de président de votre union de vous rappeler qu'à chaque année tous les ouvriers syndiqués font une démonstration dans le but de bien démontrer leur force aux capitalistes et aux gouvernants afin qu'on se pénètre bien de cette idée que les ouvriers sont d'une classe dont il faut ni maltraiter ni fouler aux pieds les droits et les libertés ${ }^{58}$.

On en profite pour souligner la nécessité du syndicalisme international, organisation dont on fait valoir qu'elle a permis l'amélioration du sort de la classe ouvrière après de longues années de luttes et d'efforts:

C’est notre devoir, rappelle en 1947 le président et le secrétaire de la Fédération provinciale du travail, d'admirer le splendide travail des pionniers du Mouvement International qui se sont imposé tant de peines, tant de privations et tant de sacrifices, pour nous léguer un si précieux héritage. C’est à eux que

56. Le Monde Ouvrier, 3 septembre 1932, 1.

57. Sur la signification de la fête, voir notamment le texte paru à deux reprises: «Honneur au travail», Le Monde Ouvrier, 30 août 1930, 1; août 1949, 1.

58. La Presse, 31 août 1917,11 
nous devons de recevoir les salaires raisonnables qui ont chassé de nos foyers la misère et la pauvreté ${ }^{59}$.

Le passé leur apparaît garant d'un avenir meilleur pour les travailleurs en autant qu'ils joignent les rangs du Travail Organisé, c'est-à-dire ceux des syndicats internationaux.

Cependant, les syndicats ne défilent pas avec l'intention de protester contre le système économique ou dans un esprit de défiance envers le patronat ou les autres classes de la société. Dans leurs discours, les leaders syndicaux font souvent valoir la nécessité de la coopération entre le Capital et le Travail tout en réclamant qu'on respecte «la justice et les droits du peuple».

Cet immense ralliement des vraies forces de la démocratie, précise le secrétaire du CMTM en 1917, constitue un sublime avertissement aux autres forces qui journellement les assaillent. C'est aussi un appel vers l'entente, la coopération auxquelles les deux grandes classes de la société aspirent également, mais dont de sots préjugés empêchent la réalisation ${ }^{60}$.

L’organisation très ordonnée du défilé révèle le caractère respectable et l'intention réformiste de la manifestation à l'exemple de celle dans les autres villes canadiennes ${ }^{61}$. Plusieurs autres signes le démontrent: des policiers encadrent la marche, des drapeaux patriotiques sont brandis et surtout les dirigeants politiques sont invités à se joindre au défilé. Comme nous l'avons souligné, le maire de Montréal participe presque toujours au défilé tout comme des échevins, députés et ministres provinciaux et fédéraux. La manifestation appelle donc à célébrer de manière symbolique la force du syndicalisme et l'identité de la classe ouvrière, tout en respectant l'ordre et l'autorité établis.

\section{LA FÊTE VUE PAR LES ÉDITORIALISTES ET LES HOMMES POLITIQUES}

En réponse, les nouveaux quotidiens montréalais d'information, qui apparaissent à la fin du XIX ${ }^{e}$ siècle, font une large place à la célébration tant pour annoncer la programmation que pour en rendre compte le lendemain ${ }^{62}$. Il n'est pas rare que les journaux La Presse, La Patrie, The Montreal Star, qui ont des tirages beaucoup plus importants que les tradi-

59. Le Monde Ouvrier, août 1947, 1.

60. Le Monde Ouvrier, $1^{\mathrm{er}}$ septembre 1917, 3.

61. G. Heron et S. Penfold, The Workers' Festival..., op. cit., xiii-xv et 43-66.

62. Voir sur le même sujet l'analyse de James Lahey, The Cultivation of Healthy Ideas : Labor Day in the Montreal Press 1886-1950, mémoire de maîtrise (histoire), Université d'Ottawa, 1975, 129. 


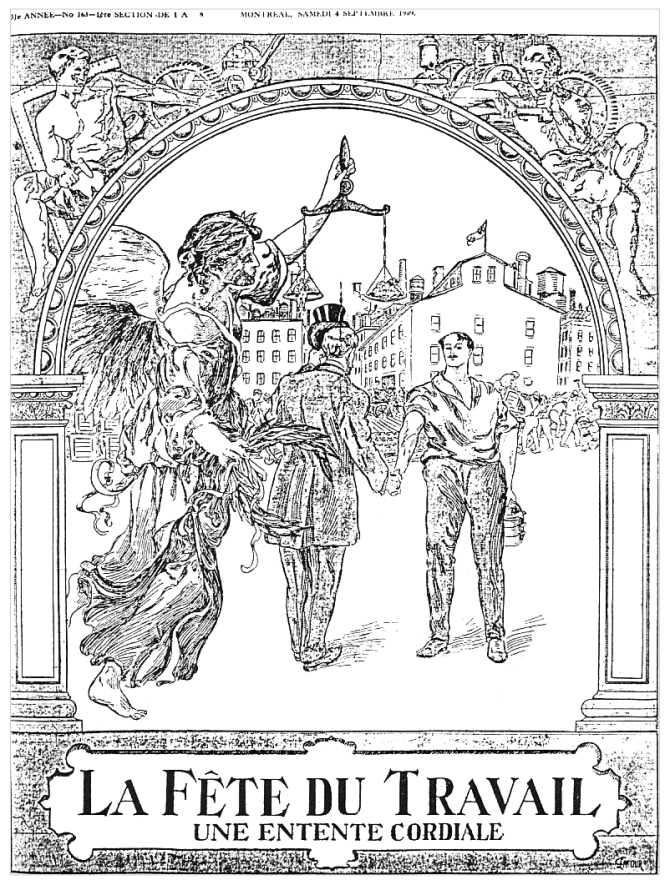

Illustration par La Patrie de la bonne entente devant régner entre le capital et le travail.

Source: La Patrie, 4 septembre 1909, 1.

tionnels journaux politiques ${ }^{63}$, consacrent une page complète, souvent à la une avant la Première Guerre mondiale, pour célébrer la noblesse du travail et rendre hommage aux travailleurs.

Désireux d'élargir leur lectorat en s'identifiant au milieu ouvrier, ils mettent en évidence, au tournant du siècle, les dirigeants syndicaux et saluent la contribution des travailleurs à la société industrielle. L'éditorialiste de La Patrie reconnaît en 1904 que la fête marque «le réveil des classes laborieuses» qui «n'ont occupé qu’une bien faible place dans l'esprit des gouvernants» et qui sont «maintenant décidés à cesser de ne jouer qu'un rôle passif dans notre état social ${ }^{64} »$. Et l'éditorialiste du Montreal

63. Les trois quotidiens montréalais, que nous avons retenus, ont de loin les tirages les plus importants dans la première moitié du $\mathrm{XX}^{\mathrm{e}}$ siècle selon l'Audit Bureau of Circulations. Ainsi, en 1920, La Presse vend quotidiennement 146581 copies, La Patrie, 27 716, The Montreal Dairly Star, 106 557, Le Devoir, 14 520, The Gazette, 30 460, The Herald, 22000 (Canadian Almanac and miscellaneous directory, 1921), 364-365. La Patrie, comme quotidien, est absorbée par La Presse en 1933. En éditorial, le journal The Gazette prend des positions nettement plus défavorables au syndicalisme pendant toute la période étudiée alors que Le Devoir, de sa fondation en 1910 jusqu’à 1947, favorise le syndicalisme catholique et dénonce en éditorial «les dangers de l'internationalisme syndical». J. Lahey, op. cit., 57, 67-69, 82-83, 113 ; Jacques Rouillard, «Le syndicalisme, 1910-1978», dans Robert Lahaise, dir., Le Devoir, reflet du Québec au 20 siècle (Montréal, Hurtubise HMH, 1994), 279-286).

64. La Patrie, 6 septembre 1904, 3. 
Star de renchérir: «It is not so long that we have had Labor Day in Canada. The setting apart of this "day" in honor of Labor was a formal recognition of the growing power of that element in the community ${ }^{65} \ldots$ "

Le syndicalisme international est accueilli positivement pour avoir contribué à l'amélioration du sort des travailleurs. L'éditorialiste de $\mathrm{La}$ Presse note que «la position importante qu'occupe aujourd'hui la classe ouvrière est, sans contradiction possible, l'œuvre des unions ouvrières ${ }^{66}{ }^{\prime}$. Cependant, il importe que les syndicats collaborent avec le monde patronal et se montrent responsables: «L'alliance du capital et du travail assurera le bonheur des familles, la paix sociale. Pour qu'elle dure, il faut que l'un et l'autre sachent rester constamment dans les limites de leurs droits et de leurs devoirs ${ }^{67}$. " Les éditorialistes mettent souvent en évidence le calme des relations de travail au Québec ou au Canada, alors que les grèves et les conflits perturbent la paix sociale aux États-Unis ou en Europe. Ils en félicitent les travailleurs montréalais.

À partir du milieu des années 1920, on ne retrouve plus dans ces journaux le même enthousiasme et la même importance accordée au premier lundi de septembre. Leur désir de s'identifier à la classe ouvrière s'estompe. Les éditorialistes s'épanchent toujours sur le sens de la fête, mais les comptes rendus de la célébration sont reportés loin à l'intérieur du journal. De plus, l'espace qui leur est consacré occupe une place beaucoup moins importante même si la participation des syndiqués au défilé est aussi imposante qu'au début du siècle. Les éditorialistes ne remettent pas en question que la fête soit celle des travailleurs salariés ou de la classe ouvrière, mais ils insistent bien davantage sur les devoirs des salariés que sur leurs droits. Ils partagent les messages d'harmonie sociale des autorités politiques et religieuses à l'occasion de la fête du Travail:

Les masses laborieuses, écrit l'éditorialiste de La Presse en 1925, sont en proie à des influences pernicieuses auxquelles elles doivent résister si elles ne veulent pas se laisser entraîner à leur propre perte et causer un tort irréparable à l'humanité, dont elles forment l'une des principales armatures. Une adhésion généreuse et entière aux enseignements de la religion catholique préservera seule nos ouvriers contre ces multiples dangers ${ }^{68}$.

65. The Montreal Daily Star, 4 septembre 1911, 3.

66. La Presse, 31 août 1907, 18.

67. La Patrie, 3 septembre 1901, 4.

68. La Presse, 3 septembre 1925, 6. 
La crainte que la classe ouvrière ne bouleverse l'ordre social comme en Europe colore l'orientation des éditoriaux.

On récuse le radicalisme ouvrier et dénonce les grèves parce qu'elles ont un effet destructeur et ne profitent pas aux travailleurs: "There never has been anything gained by the strike or lock out save an increase of bitterness and animosity, a stimulating of those passions and antagonism which are the brakes on the wheels of the industrial machinery ${ }^{69}$." La crise économique des années 1930 et la Deuxième Guerre mondiale renforcent le discours sur le fait que la collaboration patronale ouvrière est un ingrédient essentiel au progrès, à l'emploi et à l'effort de guerre : «Félicitons les travailleurs canadiens, peut-on lire en 1935, de n'avoir pas perdu la tête dans le malheur et de préférer encore les solutions de raison et de patience (les deux vont souvent ensemble), aux promesses immenses mais dangereuses d'une poignée d'agitateurs ${ }^{70}$. " Et l'éditorialiste de $L a$ Presse de suggérer en 1947: «Une franche coopération entre les diverses classes de la communauté n’a jamais été si désirable qu’à notre époque ${ }^{71}$.» Le changement de ton des éditorialistes dans les années 1920 n’est pas sans lien avec la "révolte ouvrière " marquée par l'explosion de conflits de travail de 1919 à 1921 (159 arrêts de travail au Québec) ${ }^{72}$. Cette orientation s'explique également, comme nous le verrons plus loin, par la volonté du clergé catholique de diffuser une vision bon ententiste des relations de travail.

À partir des années 1930, les hommes politiques font parvenir des messages de circonstance pour honorer les travailleurs. Reproduits textuellement dans les journaux, ils s'inscrivent dans le même esprit que ceux des éditorialistes. Les messages provenant du ministre du Travail, et parfois du premier ministre du Québec, ne manquent pas de célébrer «la grandeur du travail», invitant les ouvriers à se rendre compte de leur situation privilégiée. Le message est l'occasion de mettre en évidence les réalisations du gouvernement pour la classe ouvrière et de présenter la collaboration du Capital et du Travail comme un ingrédient indispensable au progrès économique et social. Ainsi, en 1950, le ministre du Travail,

69. The Montreal Daily Star, 5 septembre 1927, 8

70. La Presse, 31 août 1935, 22.

71. La Presse, 30 août 1947, 24.

72. Il s'est perdu 1311225 jours de travail au Québec pendant ces trois années, niveau qui ne sera dépassé que dans les années 1960. Douglas Cruikshank et Gregory S. Kealey, «Strikes in Canada,1891-1950», Labour/Le Travail, 20 (automne 1987): 90-91, 120-122. 
Antonio Barrette, signale que «le Québec donne toujours l'exemple de l'ordre dans le progrès $\mathrm{s}^{73}$ ".

Avec l'élection de l'Union nationale en 1936, le ministre du Travail ne participe plus au défilé des unions internationales. Et geste significatif, le premier ministre Maurice Duplessis assiste en 1936 et 1937 à la cérémonie religieuse à l'Oratoire Saint-Joseph associée au syndicalisme catholique ${ }^{74}$. C'est l'époque où les syndicats internationaux, qui sont accusés d'être des organisations communistes, ont maille à partir avec le gouvernement de l'Union nationale. Dans ses messages annuels (1936-1939,1944-1952), le premier ministre Duplessis fait souvent référence à l'enseignement social de l'Église présentant le travail comme une obligation et les travailleurs sous l'angle de leur devoir: "L'union basée sur le respect des droits et des devoirs de chacun est une source de force et de bien-être et la véritable et juste coopération est une formule de salut ${ }^{75}$.»

\section{LE I er MAI, FÊTE DES TRAVAILLEURS}

Le succès de la fête du Travail amène d'autres groupes sociaux à vouloir en récupérer la signification tant à droite qu'à gauche du spectre idéologique. En 1907, le Parti socialiste de Montréal invite le Conseil des métiers à célébrer avec lui le $1^{\mathrm{er}}$ mai, fête internationale des travailleurs. Après un long débat, le Conseil refuse alléguant qu'il ne partage pas les principes socialistes et qu'il ne reconnaît pas d'autre fête du Travail que celle du premier lundi de septembre ${ }^{76}$. L'année précédente, les socialistes ont célébré pour la première fois le $1^{\mathrm{er}}$ mai avec beaucoup d'éclat, drapeau rouge en tête. Une fois devant l'immeuble de la succusale de l'Université Laval à Montréal (qui est alors au centre-ville), certains manifestants - ils sont cinq à six cents dont plusieurs Juifs immigrés récemment d'Europe centrale - se mettent à crier à pleins poumons le slogan anticlérical: «À bas la calotte ${ }^{77}$ !» La démonstration fait scandale de sorte que, l'année suivante, la police à cheval disperse violemment les manifestants qui sont

73. La Presse, 2 septembre 1950, 29.

74. Il est probable que la décision du premier ministre Duplessis de ne plus participer à la fête des syndicats catholiques par la suite ait un lien avec la vive altercation qu'il a eue avec Philippe Girard lors d'une réception ayant suivi la célébration religieuse. Girard était président du Conseil central des syndicats catholiques de Montréal et organisateur du syndicat des métallos de Sorel alors en grève, Le Devoir, 22 septembre 1937, 3.

75. La Presse, 3 septembre 1949, 27.

76. La Patrie, 22 février 1907, 3 ; La Presse, 22 février 1907, 11 ; Procès-verbal du Comité exécutif du Conseil des métiers et du travail de Montréal, 21 février 1907, 172, Service des archives et de gestion des documents, UQAM, Fonds du CMTM (103P-162).

77. La Patrie, 2 mai 1906, 1. 


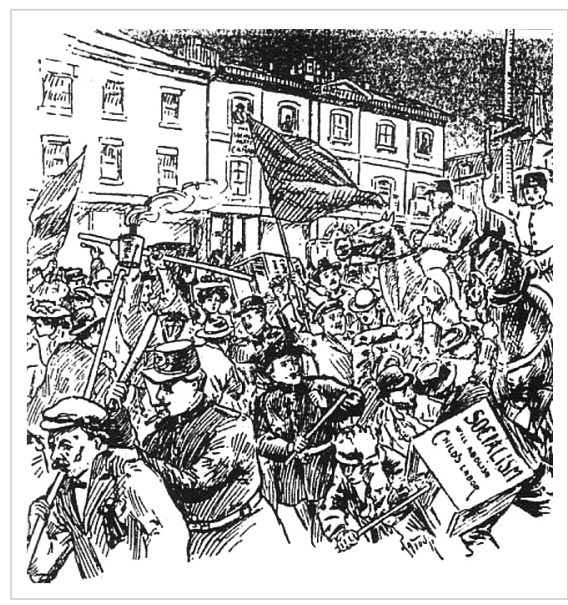

Répression par la police municipale du défilé du $1^{\text {er }}$ mai 1907.

Source: La Patrie, 2 mai 1907, 1.

chahutés par des étudiants de l'Université Laval à Montréal et des membres de syndicats internationaux ${ }^{78}$.

Dans les années subséquentes, les socialistes, et plus tard les groupes communistes, qui défilent le $1^{\text {er }}$ mai, ont souvent maille à partir avec les policiers car les autorités municipales n'apprécient guère leurs idées révolutionnaires ${ }^{79}$. Cependant, la manifestation, même dans les années 1930, ne réunit qu'un nombre bien réduit de participants puisque ces groupes demeurent faibles à Montréal. Les syndicats internationaux rejettent évidemment toute idée d'un renversement du système capitaliste, estimant plutôt que le capital et le travail poursuivent des rôles complémentaires.

Le projet de consacrer le $1^{\mathrm{er}}$ mai aux travailleurs est issu du congrès de fondation de la Deuxième internationale à Paris en 1889 . On veut rappeler la lutte aux États-Unis pour la journée normale de travail de huit heures que les syndicats voulaient voir appliquer le $1^{\text {er }}$ mai 1886 . Le refus de nombreux employeurs débouche sur un mouvement de grèves dans plusieurs villes. Pendant un ralliement au Haymarket de Chicago, une bombe explose tuant 7 policiers et en blessant plus de 70 . Huit leaders ouvriers sont injustement condamnés dont quatre à la peine capitale qui seront pendus. Le procès, qui a de larges échos en Europe, contribue sûrement à sensibiliser les délégués au congrès de Paris de 1889 à la lutte des syndiqués américains pour la journée de huit heures. Toujours est-il qu'ils adoptent une résolution faisant du $1^{\text {er }}$ mai, le jour de la fête internationale des travailleurs ${ }^{80}$. Elle commence à être célébrée timidement dans les

78. The Gazette, $1^{\text {er }}$ et 2 mai 1907, 4. Le CMTM a refusé par un vote très serré de censurer le maire pour avoir interdit le défilé socialiste, La Patrie, 3 mai 1907, 3; La Presse, 3 mai 1907, 11; The Montreal Daily Star, 3 mai 107, 13.

79. Claude Larivière, Le $1^{\text {er }}$ mai, fête internationale des travailleurs (Montréal, Éditions Albert Saint-Martin, 1975), 28-45.

80. Quoique la véritable raison de choisir le $1^{\mathrm{er}}$ mai pour voir appliquer la journée de huit heures soit obscure, il est probable que les syndicats aient adopté cette date parce qu'elle marque le début du printemps et qu'elle est le moment où les syndicats de la construction invitent les employeurs 
années 1890 pour regrouper des foules considérables au cours de la décennie suivante et devenir, au $\mathrm{XX}^{\mathrm{e}}$ siècle, la fête par excellence des travailleurs à l'extérieur de l'Amérique du Nord ${ }^{81}$.

Fait assez paradoxal, c'est donc en référence à un événement qui est survenu aux États-Unis que cette date est choisie. Mais les syndicats étatsuniens vont ignorer cette célébration car ils ont déjà leur fête du Travail depuis 1884, soit cinq ans avant le congrès de Paris. Lorsqu'elle est célébrée par des groupes socialistes au début du $\mathrm{XX}^{\mathrm{e}}$ siècle, l'American Federation of Labor en vint à la considérer comme une fête "unamerican" appartenant à la tradition radicale européenne. À Montréal, les syndicats internationaux considèrent aussi la fête du $1^{\mathrm{er}}$ mai comme une manifestation socialiste à laquelle ils refusent de participer ${ }^{82}$. Ce n'est que beaucoup plus tard, dans les années 1970, qu'ils se réconcilient avec le $1^{\text {er }}$ mai alors que le premier lundi de septembre a perdu toute signification.

\section{LA FÊTE SOUS LE REGARD DES AUTORITÉS RELIGIEUSES}

À Montréal, la menace que fait peser le clergé catholique sur les syndicats internationaux se révèle plus sérieuse que celle des groupes socialistes. En effet, l'épiscopat catholique s'émeut de leur expansion au Québec au début du siècle. Deux grèves importantes à Montréal en 1903 et la venue, la même année, dans la métropole de Samuel Gompers, président de l'American Federation of Labor, décident l'archevêque de Montréal, $\mathrm{M}^{\mathrm{gr}}$ Paul Bruchési, à mettre en garde, dans une lettre pastorale, les catholiques contre les unions internationales qui «n'ont rien de commun avec nos dispositions de tempérament, avec nos mœurs et nos croyances ${ }^{83}$ ». L'année suivante, il veut influer sur le sens de la fête en proposant au Conseil des métiers et du travail de faire précéder le défilé du premier lundi de septembre d'une messe célébrée à la basilique Notre-Dame ${ }^{84}$.

à appliquer de nouvelles normes déterminant les salaires et les heures de travail. Maurice Dommanget, Histoire du premier mai (Paris, Éditions de la Tête de Feuilles, 1972), 103-107; Philip S. Foner, May Day: A Short History of the International Workers' Holiday, 1886-1986 (New York, International Publishers, 1986), 17-43. Haymarket Affair, Wikipedia, http://en.wikipedia.org/wiki/ Haymarket_affair.

81. G. Deneckere et al., Premier mai, L'invention des syndicalismes. Le syndicalisme en Europe occidentale à la fin du XIXe siècle, Préactes du colloque, Paris, 13 octobre 1995, 22.

82. Le CMTM refuse à plusieurs reprises de se joindre au défilé du $1^{\mathrm{er}}$ mai, que l'invitation vienne des organisateurs de la fête ou de délégués à l'intérieur même du CMTM. La Presse, 8 avril 1921, 1; La Patrie, 20 avril 1923, 13; Le Monde Ouvrier, 21 avril 1928, 1; 9 mars 1929, 9 mai 1936, 4.

83. J. Rouillard, Les syndicats nationaux..., op. cit., 171.

84. À Montréal, une messe basse est célébrée tôt le lundi matin à l'église Notre-Dame de 1892 à 1894 avant que le défilé s'ébranle. L’assemblée Grande Hermine des Chevaliers du travail en avait 


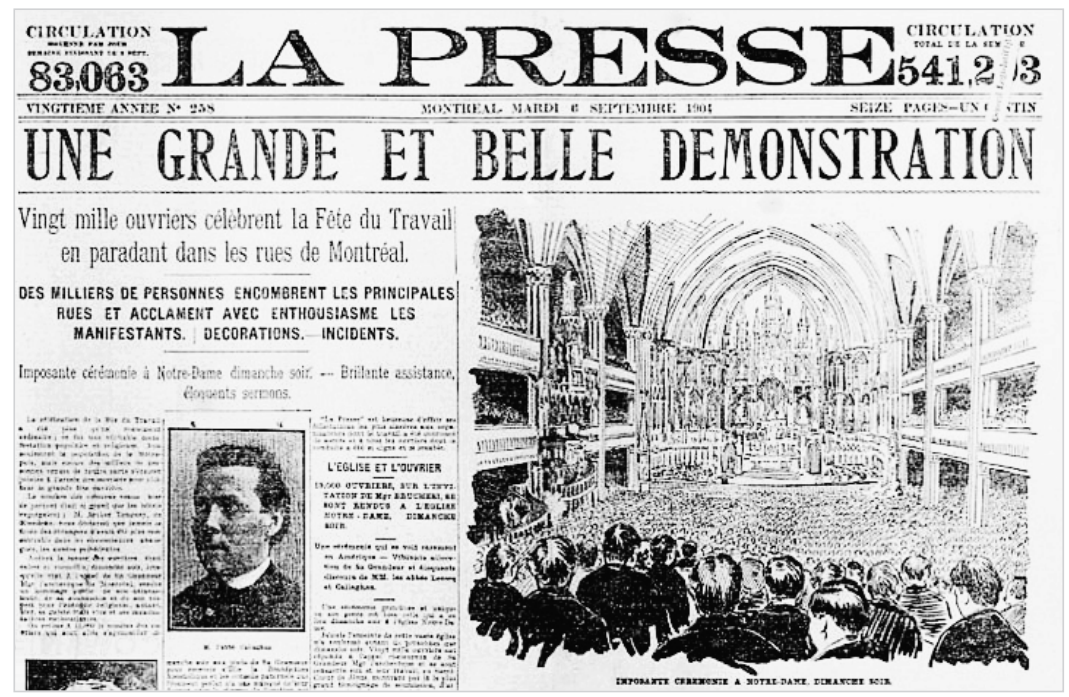

Messe célébrée à la basilique Notre-Dame en l'honneur de la fête du Travail, le 4 septembre 1904

Source: La Presse, 6 septembre 1904, 1.

Mais les dirigeants syndicaux refusent, alléguant que la fête ne doit pas avoir de caractère religieux puisqu'elle est commune aux travailleurs de toute confession religieuse ${ }^{85}$. Ils suggèrent à l'archevêque une solution de rechange, soit une messe le dimanche précédant le premier lundi de septembre.

Effectivement, à partir de 1904, une messe en l'honneur des travailleurs est célébrée à la basilique Notre-Dame le dimanche soir. Dans une lettre pastorale y invitant les travailleurs, $\mathrm{M}^{\mathrm{gr}}$ Bruchési présente l'Église catholique dans une perspective nouvelle, en tant que protectrice des travailleurs qui ont bien sûr des devoirs, mais jouissent aussi de droits comme d'obtenir des conditions de travail décentes et des salaires équitables répondant «aux légitimes besoins des familles ${ }^{86}$ ». Quant au prédicateur,

fait la demande. À Québec, une messe est également célébrée chaque année, le lundi matin, depuis la première célébration de la fête du Travail en 1891. C'est le cas aussi à Saint-Hyacinthe, Sherbrooke et Valleyfield en 1907. L'Événement, 2 septembre 1891, 2 ; 4 septembre 1897, 4; La Presse, 6 septembre 1892, 4; 2 septembre 1893, 7; 4 septembre 1894, 5.

85. La Presse, 30 août 1904, 4. En 1938, un syndicat international à Montréal invite tous les syndiqués de foi catholique à assister à une messe, avant le défilé, célébrée dans une église paroissiale à la mémoire des membres des unions internationales décédés. Cette initiative intervient à un moment où les journaux catholiques accusent les syndicats internationaux d'orientation communiste. La Presse, 3 septembre 1938, 45.

86. La Presse, 29 août 1904, 2. 
il insiste dans son sermon à Notre-Dame, où les fidèles sont très nombreux, que l'Église a toujours eu une attention particulière pour l'ouvrier et qu'elle détient la solution des questions sociales ${ }^{87}$. L'année suivante, $\mathrm{M}^{\mathrm{gr}}$ Bruchési reconnaît le droit des travailleurs de former des syndicats en autant «qu'ils ne viennent contredire les droits clairement établis et ne réclament point des choses qui seraient évidemment contre l'ordre social ${ }^{88}$ ». Une messe spécifique pour les anglophones est organisée à l'église Saint-Patrick à partir de 1905.

Les années suivantes, les sermons à Notre-Dame sont parfois l'occasion d'écorcher les syndicats internationaux accusés de faire fi de la religion et de la morale catholiques. Ainsi, en 1906, $\mathrm{M}^{\mathrm{gr}}$ Émard, évêque de Valleyfield, invite les ouvriers à s'éloigner des unions «dont le but n'est pas avoué et dont les directeurs sont inconnus» et il exprime le souhait que les ouvriers canadiens forment des syndicats canadiens au lieu de joindre des unions internationales ${ }^{89}$. Trois ans plus tard, $\mathrm{M}^{\mathrm{gr}}$ Bruchési, dans son homélie, met en garde les ouvriers contre les sociétés neutres qui «ne s'occupent pas de religion" ou des sociétés d'affaires «qui n'ont pas d'idéal» et qui en ne parlant que d'affaires s'abstiennent de parler de religion et de morale ${ }^{90}$. L'allusion touche évidemment les syndicats internationaux qui se défendent d'aborder des questions religieuses et de se mêler de la religion de leurs membres.

Cet argumentaire pave la voie à la formation de syndicats catholiques qui prennent leur envol à Montréal en 1914 et qui mettent sur pied un Conseil central national et catholique en 1920 pour chapeauter ces syndicats. Cette année-là, c'est l'aumônier général des syndicats catholiques de Montréal, l'abbé Edmour Hébert, qui est chargé de l'homélie à NotreDame. Il s'en prend sans ambages aux «unions neutres» qui font «une véritable injure à la foi catholique» «en excluant Dieu et la religion» de l'action syndicale. L'enseignement papal ferait un devoir aux ouvriers catholiques «de se regrouper dans des associations nettement confessionnelles pour la défense de leurs intérêts et la protection de leurs droits". Seule l'Église, "gardienne indéfectible de la vérité éternelle $[\ldots]$ peut

87. Le journal La Patrie rapporte que l'église était archi-comble. La Patrie, 6 septembre 1904, 4.

88. La Patrie, 5 septembre $1905,8$.

89. La Patrie, 4 septembre 1906, 8. L'éditorialiste de La Patrie fait remarquer que c'est peut-être souhaitable, mais qu'il ne faut pas perdre du vue que des milliers d'ouvriers canadiens font partie de syndicats internationaux depuis longtemps et qu'ils perdraient les sommes considérables qu'ils ont versées, La Patrie, 8 septembre 1906, 10 ; Le Soleil, 5 septembre 1906, 1.

90. La Patrie, 7 septembre 1909, 11. 
fournir les principes capables de fixer avec certitude les relations entre le capital et le travail ${ }^{91}$ ».

L'année suivante, les autorités religieuses annulent les messes du dimanche soir à Notre-Dame et à Saint-Patrick. Elles les remplacent par une messe solennelle à l'Oratoire Saint-Joseph (imposante basilique alors en construction dédiée au patron des ouvriers) à laquelle sont invités les travailleurs et leur famille. À partir de 1924, les syndicats catholiques s'amènent à l'Oratoire en défilé avec bannières et fanfare depuis la cour du collège Notre-Dame situé en face de l'Oratoire ou de la cour du collège Jean-de-Brébeuf situé pas très loin de l'Oratoire non plus. Il n'y a pas véritablement de défilé dans les rues, probablement parce que les syndiqués catholiques sont beaucoup moins nombreux à Montréal que les syndiqués internationaux (3248 membres en 1924) ${ }^{92}$. Il devient alors gênant de marcher avec de minces effectifs alors que le défilé des internationaux attire des milliers de syndiqués ${ }^{93}$. Pour la journée du lundi, les syndicats catholiques invitent leurs membres à une fête champêtre en après-midi dans un grand parc en périphérie de la ville où sont prévus des jeux et des amusements populaires.

Dans les années 1920 et 1930, les autorités religieuses, qui ont toute autorité sur l'organisation de la manifestation, accentuent leur orientation spirituelle. La célébration religieuse faite en plein air face à l'Oratoire Saint-Joseph est présidée par l'archevêque de Montréal assisté de plusieurs dignitaires religieux. Sont conviés non seulement les travailleurs salariés, mais les fidèles en général afin de rendre hommage au travail et aux travailleurs. Elle attire alors une foule imposante s'élevant entre 20000 à 50 000 personnes, composée de travailleurs avec leur famille et de nombreux pèlerins. Les membres de la Jeunesse ouvrière catholique, mouvement d'action catholique, s'ajoutent à la fin des années 1930. Cette célébration religieuse jette de l'ombre sur le défilé des syndicats internationaux, car les quotidiens montréalais lui accordent autant d'importance, sinon plus, même si les syndiqués catholiques sont beaucoup moins nombreux à Montréal. De plus, les éditorialistes intègrent de plus en plus à leur analyse la dimension religieuse de la fête.

91. La Presse, 7 septembre 1920, 1 et 9; La Patrie, 7 septembre 1920, 8.

92. Les effectifs des syndicats catholiques à Montréal sont six fois moins nombreux que ceux du CMTM dans les années 1920 et quatre fois moins dans les années 1930 (Ministère du Travail du Canada, Organisations des travailleurs au Canada, Mouvement syndical ouvrier au Canada, 1911-1940).

93. Dans la ville de Québec où les syndiqués catholiques sont plus nombreux, leur défilé emprunte un parcours dans les rues de la ville. 
Dans un sermon de circonstances à l'Oratoire, un prédicateur évoque habituellement la sollicitude de l'Église catholique à l'égard des travailleurs, la nécessité du syndicalisme et le devoir des travailleurs de joindre le syndicalisme catholique. Ainsi, en 1940, dans son homélie radiodiffusée dans tout le Canada, le père Jean d'Auteuil Richard évoque le fait que «l'internationalisme met notre classe ouvrière canadienne dans une situation fausse, inquiétante et qui n'est pas sans danger ", qu'il faut "envisager les problèmes du travail dans la perspective inépuisablement riche du dogme catholique» et que les évêques au Québec "ont jugé de l'opportunité et de la nécessité de doter notre classe ouvrière catholique d'un syndicalisme parfaitement adapté aux exigences profondes de sa foi et de sa philosophie de la vie ${ }^{94}$ ». À propos du défilé des internationaux, l'abbé L. Lafortune, assistant directeur des œuvres sociales du diocèse, le caractérise en 1925, toujours pendant la célébration à l'Oratoire, comme étant « un défilé anonyme et bizarre, sans signification et sans but ${ }^{95}$ ».

Après la Deuxième Guerre mondiale, la sacralisation de la fête, sa dimension pieuse, s'accentue. La participation syndicale est encore davantage marginalisée avec la suppression du court défilé des syndiqués catholiques à partir de 1946. À la messe solennelle célébrée en plein air à l'Oratoire Saint-Joseph le dimanche en après-midi, on ajoute une procession aux flambeaux en soirée. Le glissement s'accentue si bien que la fête devient moins la fête des travailleurs que celle du travail en général. En 1956, les autorités religieuses font officiellement du premier lundi de septembre la fête de Saint-Joseph artisan et les travailleurs sont invités à apporter leurs outils pour les faire bénir. De plus, non seulement les dirigeants des syndicats catholiques sont-ils invités, mais également ceux de plusieurs mouvements d'action catholique qui ne sont pas liés au monde ouvrier ${ }^{96}$.

L'aumônier général de la CTCC au Québec, Henri Pichette, rend compte alors de la nouvelle définition de cette "fête chrétienne» en 1956: "L’Église, au lieu d'isoler les travailleurs catholiques dans une fête à part, les invite à communier intimement et fraternellement avec tous les autres travailleurs dans leur aspiration légitime en leur apportant en plus leur propre témoignage ${ }^{97}$.» En 1959, le supérieur de l’Oratoire invite à la célébration tous les ouvriers, cols blancs et même les membres des professions

94. La Presse, 3 septembre 1940, 16.

95. La Presse, 4 septembre 1925, 3.

96. La Presse, $1^{\text {er }}$ septembre 1956, 35. À la fin des années 1950, on ajoute aussi une cérémonie spécifique en après-midi pour les travailleurs blessés dans des accidents du travail.

97. Le Devoir, $1^{\text {er }}$ septembre 1956, 4. 
libérales ${ }^{98}$. La manifestation a ainsi perdu son sens original d'honorer les travailleurs syndiqués pour devenir un hommage religieux célébrant tous ceux qui effectuent un travail.

\section{DÉCLIN}

La participation des syndiqués internationaux au défilé de la fête du Travail et aux manifestions qui l'accompagnent perd beaucoup de son lustre après la Deuxième Guerre mondiale. C’est moins de 5000 syndiqués qui défilent dans les rues alors que les effectifs du Conseil des métiers et du travail atteignent plus de 70000 membres. Un vieux leader ouvrier, Gustave Francq, s'en plaint en 1948: "On n’a plus la fête du Travail d'antan, alors qu'il n'était pas rare de voir parader [sic] un syndicat avec 100 pour cent de ses membres et qu'il n'y avait pas assez de fanfares dans le district de Montréal pour suffire à la demande ${ }^{99}$.» En 1940, le défilé est annulé en raison du mauvais temps et, pour la première fois en 1944, il n'est pas organisé, officiellement pour éviter d'interrompre le travail dans les usines de guerre ${ }^{100}$. Mais des divisions à l'intérieur du CMTM entre une aile plus radicale et une autre plus modérée jouent certainement aussi un rôle dans cette décision. Toujours est-il qu’il devient par la suite très difficile de mobiliser à nouveau les syndiqués pour défiler.

Le défilé étant à nouveau contremandé en 1952 en raison d'une pluie torrentielle, le Conseil des métiers et du travail prend le parti, l'année suivante, de le remplacer par un spectacle de variétés dans une vaste salle ${ }^{101}$. Le spectacle a d'abord lieu au Palais du Commerce, puis au Forum et au Chalet de la Montage, toujours suivi d'une invitation à se rendre au parc Belmont. La participation des syndiqués devient passive, invitée à un spectacle de variétés de plus en plus offert par des professionnels de la scène. C'en est donc fini du défilé traditionnel, de l'occupation par des travailleurs de l'espace public et d'une implication personnelle des syndiqués.

La formule du spectacle en salle est abandonnée en 1962, remplacée par une réception du maire Jean Drapeau au Chalet de la Montagne pour les dirigeants du Conseil du travail de Montréal et les permanents syndicaux. À la même occasion est lancée la semaine de promotion des étiquettes syndicales apposées sur les produits de fabrication syndicale afin

98. La Presse, 5 septembre 1959, 28; 6 septembre 1960, 23.

99. Le Monde Ouvrier, 3 septembre 1948, 1.

100. Le Monde Ouvrier, 19 août 1944; 2 septembre 1944, 12.

101. La Presse, 2 septembre 1952, 26. 
Publicité de la bière Molson montrant que la fête du Travail, autrefois célébrée par un défilé animé, est devenue l'occasion d'une longue fin de semaine de repos.

Source: La Presse, 30 août 1958, 22.

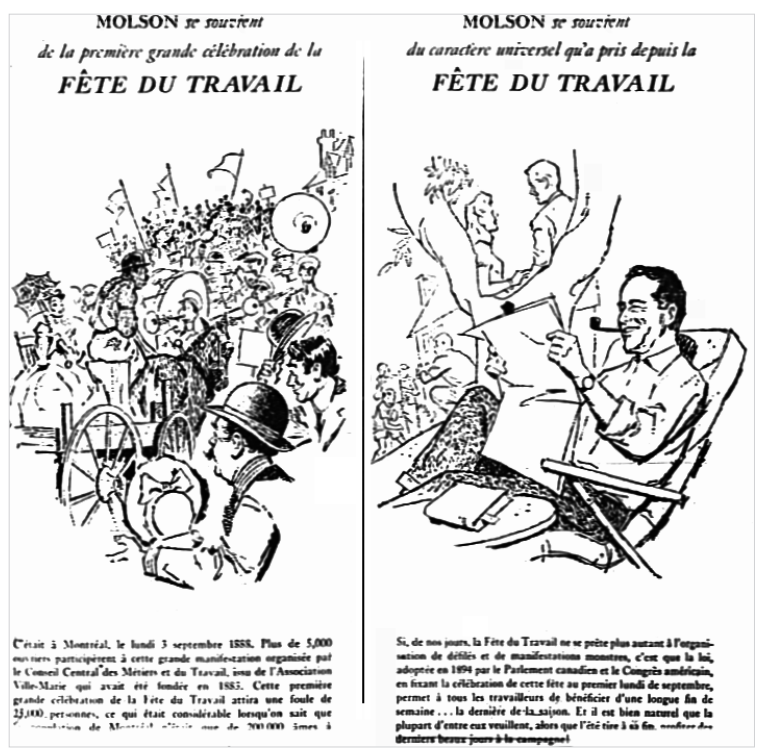

de les faire connaître à la population ${ }^{102}$. Cette activité est abandonnée, l'année suivante, de sorte que le premier lundi de septembre devient une simple journée de congé, une fête sans fête. Sa signification entre alors dans l'oubli parmi les syndiqués et la population en général.

Dans les années 1950, les dirigeants syndicaux montréalais expliquent la désaffection des syndiqués par le désir de beaucoup d'entre eux de s'offrir des vacances à l'extérieur de la ville pour cette dernière fin de semaine de l'été. La fête est donc en partie victime du choix du lundi pour marquer la célébration ${ }^{103}$. À l'origine, il pouvait être alléchant de prolonger le congé du dimanche par celui du lundi ; mais le samedi devenant

102. The Gazette, 3 septembre 1962, 13. Cette activité de promotion de l'étiquette syndicale a été ajoutée à la fin des années 1950 (CMTM, Procès-verbal de l'assemblée régulière, 7 mai 1953, 63, dans Sylvie Murray et Élyse Tremblay, Cent ans de solidarité. Histoire du CTM, 1886-1986 (Montréal, VLB éditeur, 1987), 52.

103. «L'amélioration continue du standard de vie de nos membres leur permettent [sic] de posséder une automobile et une maison à la campagne, les longues fins de semaine rendues possibles grâce à la semaine de travail de cinq jours sont en quelque sorte responsables de la disparition premièrement du pique-nique de la fête du Travail et maintenant de la parade [sic] de la fête du Travail. Nous sommes pleinement d'accord avec la décision prise par les délégués du Conseil parce que nous nous rendons compte que depuis quelques années nos membres semblaient s'en désintéresser en ne participant pas à la parade [sic] en nombre suffisant pour démontrer notre véritable force et solidarité ", Le Monde Ouvrier, juin-juillet 1953, 4. L'éditorialiste de La Presse retient aussi cette raison pour expliquer le déclin de la fête, La Presse, 3 septembre 1960, 4. Voir aussi G. Heron et S. Penfold, The Workers' Festival..., op. cit., 147-269. 
lui aussi un jour de relâche après la guerre, il devient alors tentant de profiter de ces trois jours de congé pour s'éloigner de la ville et visiter des parents et amis. Dans les années 1950, les journaux renferment des publicités des compagnies de chemins de fer et de navigation proposant des excursions à l'extérieur de la ville ${ }^{104}$. Comme pour d'autres fêtes, l'avènement de la société de loisirs et de consommation fait alors concurrence à la fête du Travail. Ce congé devient pour les syndiqués plus un moment de détente et de loisirs privés qu'une occasion de solidarité ouvrière dans un espace public.

Comme nous l'avons noté, les journaux mettent beaucoup moins en évidence la fête à partir de la seconde moitié des années 1920. Elle devient un événement secondaire placé loin à l'intérieur de leurs pages. C'est le moment aussi où les éditorialistes, les politiciens et les autorités religieuses insistent sur les devoirs des travailleurs et la nécessaire collaboration patronale ouvrière. La "révolte ouvrière » qui suit la Première Guerre mondiale n’est pas étrangère à ce resserrement chez les élites qui craignent que «les masses laborieuses» ne soient la proie "d'influences pernicieuses ${ }^{105}$ ».

La volonté de sacralisation de la fête par les autorités religieuses jette de l'ombre sur le sens original de la fête. Après y avoir greffé une dimension religieuse avec la célébration d'une messe à la cathédrale NotreDame, elles en font évoluer la signification encore davantage à l'Oratoire Saint-Joseph. De fête syndicale célébrant les travailleurs catholiques, elle devient graduellement une fête religieuse du travail en l'honneur de saint Joseph. Cette interprétation entre en compétition avec la signification que les syndicats internationaux veulent lui donner. Et comme la grande majorité des syndiqués sont catholiques, elle affecte certainement leur participation au défilé.

Le repli de la manifestation s'explique aussi par des transformations à l'intérieur de la classe ouvrière et du monde syndical. À partir de la Deuxième Guerre mondiale, la composition du mouvement syndical change à Montréal, comme dans le reste de l'Amérique du Nord, avec la montée des syndicats industriels qui regroupent les travailleurs par usine plutôt que par métier. En 1938, elle engendre un schisme aux États-Unis à l'intérieur de l'American Federation of Labor qui voient plusieurs unions internationales favorisant le syndicalisme industriel la quitter pour former une nouvelle centrale, le Congress of Industrial Organizations (CIO). Les

104. Dès 1927, les compagnies de chemins de fer prévoyaient atteindre un record d'affluence pour le premier lundi de septembre, The Montreal Daily Star, 3 septembre 1927, 3.

105. La Presse, 3 septembre 1925, 6. 


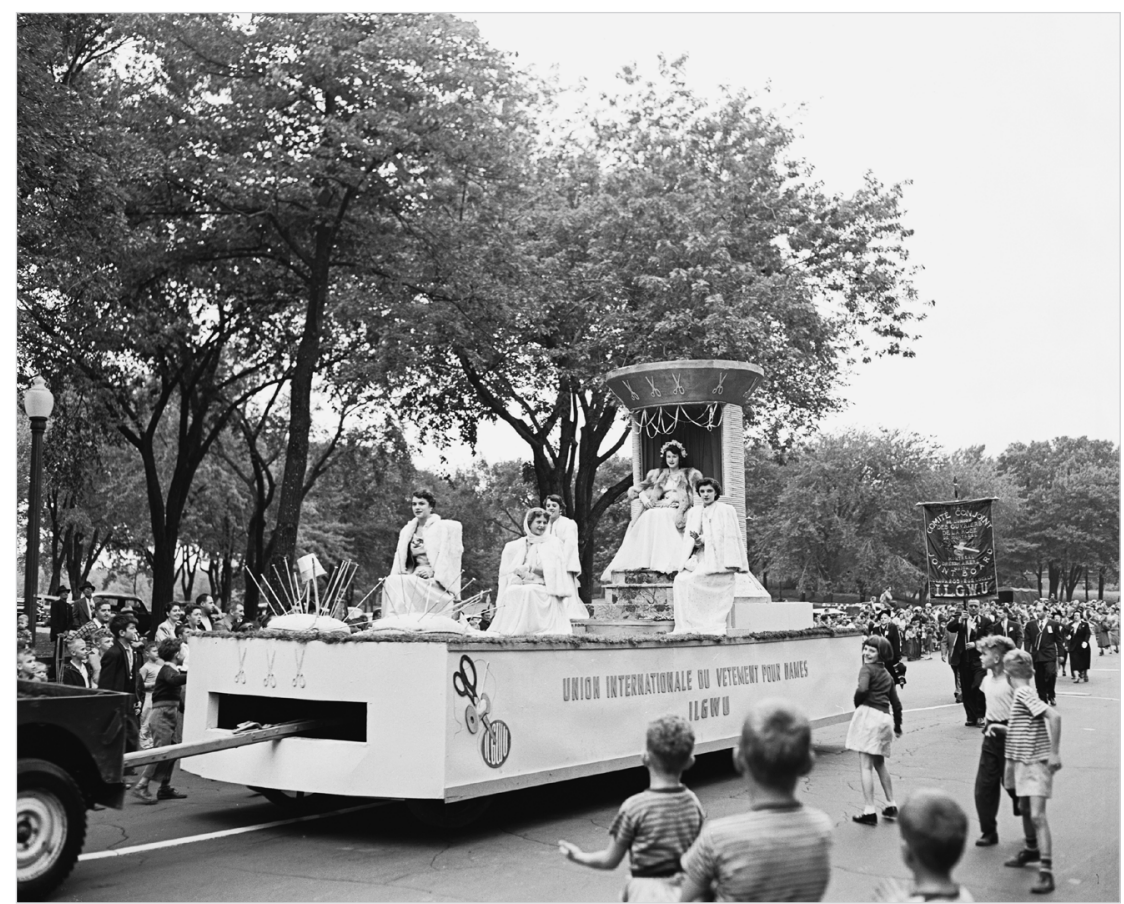

Char allégorique de l'Union du vêtement pour dames lors du défilé du 3 septembre 1950 Source: The Montreal Gazette, 4 septembre 1950, Bibliothèque et Archives Canada,

Photographies, Série 50-447-1

syndicats montréalais affiliés aux unions internationales membres du cio forment le Conseil du travail de Montréal (CTM) en 1940 qui s'abstient cependant d'organiser un défilé parallèle à celui du CMTM.

Plusieurs syndicats affiliés au CMTM sont également affectés par les transformations dans la composition de la main-d'œuvre. Alors que, depuis son origine, le CMTM se limitait plutôt à réunir des syndicats de métier, voilà que pendant la guerre, il ouvre ses rangs aux syndicats des industries du vêtement, du tabac, de l'alimentation, de la métallurgie, de l'aéronautique et du secteur des services ${ }^{106}$. Ces syndicats formés de travailleurs et de travailleuses semi-qualifiés ou non qualifiés partagent moins bien les objectifs de solidarité ouvrière et syndicale mis de l'avant par les

106. Le schisme des unions internationales aux États-Unis détermine les unions de métier affiliées à l'American Federation of Labor à assouplir leur structure et à se montrer réceptives au mode industriel de syndicalisation. C'est pourquoi, le CMTM, qui regroupait presque exclusivement des syndicats de métier, est composé majoritairement de syndicats industriels à partir de la Deuxième Guerre mondiale. B. Dionne, op. cit., 280-294. 
syndicats de métier. Leur rapport au travail n’a plus la même signification, car ils ne se reconnaissent guère dans la fierté du métier, aspiration qui faisait partie du traditionnel défilé de la fête du Travail.

La montée du syndicalisme industriel à l'intérieur même du CMTM engendre aussi des tensions dans ses rangs entre les éléments réformistes et communistes de 1942 à $1946^{107}$. Ces derniers, qui dirigent d'importants syndicats industriels, font adopter des résolutions plus radicales qui déplaisent à bon nombre de syndiqués. Les communistes sont évincés de 1945 à 1947 à la faveur de la Guerre froide, mais le mal est fait car ces résolutions donnent prise évidemment aux critiques concernant les dangers du communisme. À l'Oratoire, en 1945, le prédicateur sent le besoin de rappeler les dangers du communisme qui est «l'ennemi déclaré de l'ordre public», préconisant la lutte des classes et la suppression de la propriété privée $^{108}$. Les divisions à l'intérieur des syndicats internationaux et les mutations du marché du travail ont pour effet de contribuer à la désaffection des syndiqués de participer au défilé.

Moins importante, mais néanmoins présente comme motivation à organiser un défilé, il y a les dépenses de plus en plus importantes liées à l'embauche d'une fanfare et à la préparation d'un char allégorique ${ }^{109}$. Fabriqués avec des moyens artisanaux, les chars ne peuvent plus rivaliser avec ceux d'autres défilés, notamment ceux de la Saint-Jean-Baptiste, patronnés par des entreprises industrielles ou commerciales. D'ailleurs, dans les années 1940 et 1950, les syndicats font eux-mêmes appel au soutien d'entreprises pour financer leurs chars allégoriques. Ces derniers deviennent alors tout autant l'illustration d'un métier qu'un moyen pour les entreprises de se faire connaître. C'est une entorse à la signification initiale du défilé.

Enfin, il y a lieu de se demander si le déclin de ce symbole traditionnel du travail salarié peut également refléter chez les syndiqués un affaiblissement du sens d'appartenance à la classe laborieuse, comme on l'appelait au début du siècle. Avec la prospérité de la guerre, le sort des travailleurs syndiqués s'améliore et la fierté d'appartenir à la classe ouvrière n'a peutêtre plus la même signification. Il devient moins attrayant et peut-être gênant pour les ouvriers d'afficher publiquement dans les rues de la ville leur statut de salariés et de travailleurs manuels. La disparition de la fête deviendrait alors le reflet d'une transformation profonde des attitudes, des comportements et des rapports sociaux chez les travailleurs salariés,

107. Ibid., 175-187, 231-238.

108. La Presse, 4 septembre 1945, 12. Voir aussi Le Monde Ouvrier, 3 septembre 1948, 2.

109. The Gazette, 3 septembre 1962, 13. 
résultat d'une participation accrue à la société de consommation. En effet, le niveau de vie des travailleurs syndiqués s'améliore substantiellement après la Deuxième Guerre mondiale. La fréquentation des magasins s'intensifie pendant ce jour de congé et plusieurs acquièrent une auto, ce qui facilite les déplacements hors de la ville. C’est précisément la raison évoquée ("amélioration du standard de vie») par Le Monde ouvrier, organe des syndicats internationaux, pour justifier l'abandon du défilé en $1953^{110}$.

Cependant, cette transformation n'affecte pas le militantisme des travailleurs syndiqués car les arrêts de travail sont plus nombreux pendant la guerre et l'après-guerre et l'opposition est vive à l'égard du gouvernement de l'Union nationale. Par ailleurs, l'abandon du défilé en 1953 ne représente pas la fin définitive de l'affirmation des syndiqués sur la place publique puisque l'initiative d'une marche dans les rues de Montréal est reprise par le mouvement syndical en 1970 sous des allures bien différentes cependant.

Ce défilé, qui a lieu le $1^{\text {er }}$ mai, est le résultat d'une initiative du Conseil central des syndicats nationaux de Montréal de la CSN qui invite les syndicats de la métropole à y participer. Les présidents des trois principales centrales syndicales au Québec (FTQ, CSN, CEQ) participent à la manifestation qui aura lieu chaque année par la suite. Ses organisateurs veulent situer la fête dans le courant international de solidarité avec les travailleurs et travailleuses du reste du monde ${ }^{111}$. Le défilé ne se limite pas aux syndiqués, il comprend aussi des groupes politiques de gauche et la manifestation est teintée d'une volonté de contestation de l'ordre social et du régime capitaliste. Cette manifestation, moins importante cependant en termes de participation que celle du premier lundi de septembre, symbolise la radicalisation du mouvement syndical au Québec pendant cette décennie.

À cette époque, les initiateurs du défilé ne connaissent pas l'origine de la fête du premier lundi de septembre et l'importance qu'elle a eue dans la métropole. On croit que cette fête chômée n'est pas la véritable fête des travailleurs, mais une fête dédiée au travail en général décidée par les gouvernements sans avoir été revendiquée par les travailleurs eux-mêmes. On ajoute qu'elle a été imposée de l'étranger, par nos voisins du Sud, sans

110. Voir la citation du Monde ouvrier, note 103.

111. Michel Chartrand dirige alors le Conseil central qui se radicalise sous son leadership. L’année précédente, le Conseil a tenté d'organiser un défilé qu'il a décommandé parce que beaucoup de travailleurs, selon Michel Chartrand, assimilaient la fête à celle "des Russes et communistes», La Presse, 2 mai 1970, 2; $1^{\text {er }}$ mai 1969, 3. 
qu'elle soit véritablement voulue par les travailleurs québécois. Cette interprétation est évidemment fausse car, comme on l'a vu, le premier lundi de septembre représente la célébration d'une fête des travailleurs issue entièrement du monde ouvrier.

\section{CONCLUSION}

En occupant un espace public de choix par leur défilé dans les rues, les travailleurs et travailleuses de Montréal veulent manifester de manière symbolique la fierté et la dignité de leur travail tout comme leur identité en tant que nouvelle classe sociale. Leur démonstration de solidarité affirme la présence de la classe ouvrière sur le plan de l'imaginaire collectif. Elle montre leur contribution essentielle au développement de la société afin d'obtenir en retour une reconnaissance sociale. La célébration vise également à ce que le syndicalisme soit reconnu comme une organisation légitime des travailleurs à travers lequel s'expriment les aspirations de la classe ouvrière. Même si la célébration se situe dans un cadre institutionnel, sans volonté de contestation radicale de l'ordre social, elle témoigne de manière symbolique de la volonté d'établir une nouvelle relation de pouvoir dans la société montréalaise.

La signification de la fête articulée par les syndicats internationaux n'est pas remise en question par les éditorialistes et les élites politiques de l'époque qui y voient l'affirmation d'une classe sociale en expansion et ils reconnaissent la légitimité du syndicalisme. Cependant, cette acceptation est teintée de la crainte, à partir des années 1920, que la montée du monde ouvrier bouleverse l'ordre social comme en Europe. C'est pourquoi, ils s'appliquent à mettre l'accent sur la nécessaire collaboration patronale ouvrière et à évoquer les améliorations que l'industrialisation apporte à la condition de vie des travailleurs. L'Église catholique va plus loin que de souhaiter la paix sociale, elle veut infléchir le sens de la fête du Travail par une célébration religieuse. Son interprétation évolue graduellement depuis l'invitation à une messe lancée en 1904. Voulue au départ comme fête honorant les travailleurs syndiqués, elle est présentée dans les années 1950 comme une célébration religieuse du travail en l'honneur de saint Joseph.

Après avoir connu une grande popularité, la participation des syndiqués à la fête du Travail fléchit dans les années 1930, puis s'effrite après la Deuxième Guerre mondiale. Comme nous l'avons fait remarquer, le désir des travailleurs de s'offrir une longue fin de semaine à l'extérieur de la ville et les transformations dans la composition des effectifs syndicaux ont 
eu raison du défilé et de la fête tout entière. Sa disparition est possiblement liée aussi à un affaiblissement du sens d'appartenance à la classe ouvrière comme les ouvriers de métiers l'entendaient au début du siècle. Rapidement, la signification de cette importante fête des travailleurs est tombée dans l'oubli pour devenir un jour de congé sans raison précise, une borne symbolique marquant la fin de l'été et le début de l'automne. 